\title{
Assimilation of satellite data to optimize large-scale hydrological model parameters: a case study for the SWOT mission
}

\author{
V. Pedinotti ${ }^{1,2}$, A. Boone ${ }^{1}$, S. Ricci ${ }^{3}$, S. Biancamaria ${ }^{4}$, and N. Mognard ${ }^{2}$ \\ ${ }^{1}$ CNRM/GAME, Météo-France, CNRS, URA 1357, Toulouse, France \\ ${ }^{2}$ Centre National d'études spatiales (CNES), Toulouse, France \\ ${ }^{3}$ CERFACS/URA 1875, 42 Avenue Gaspard Coriolis, 31057 Toulouse CEDEX, France \\ ${ }^{4}$ CNRS, LEGOS, UMR5566 CNRS-CNES-IRD-Université Toulouse III, France \\ Correspondence to: V. Pedinotti (vanessa.pedinotti@gmail.com)
}

Received: 3 March 2014 - Published in Hydrol. Earth Syst. Sci. Discuss.: 30 April 2014

Revised: 20 September 2014 - Accepted: 23 September 2014 - Published: 10 November 2014

\begin{abstract}
During the last few decades, satellite measurements have been widely used to study the continental water cycle, especially in regions where in situ measurements are not readily available. The future Surface Water and Ocean Topography (SWOT) satellite mission will deliver maps of water surface elevation (WSE) with an unprecedented resolution and provide observation of rivers wider than $100 \mathrm{~m}$ and water surface areas greater than approximately $250 \times 250 \mathrm{~m}$ over continental surfaces between $78^{\circ} \mathrm{S}$ and $78^{\circ} \mathrm{N}$. This study aims to investigate the potential of SWOT data for parameter optimization for large-scale river routing models. The method consists in applying a data assimilation approach, the extended Kalman filter (EKF) algorithm, to correct the Manning roughness coefficients of the ISBA (Interactions between Soil, Biosphere, and Atmosphere)-TRIP (Total Runoff Integrating Pathways) continental hydrologic system. Parameters such as the Manning coefficient, used within such models to describe water basin characteristics, are generally derived from geomorphological relationships, which leads to significant errors at reach and large scales. The current study focuses on the Niger Basin, a transboundary river. Since the SWOT observations are not available yet and also to assess the proposed assimilation method, the study is carried out under the framework of an observing system simulation experiment (OSSE). It is assumed that modeling errors are only due to uncertainties in the Manning coefficient. The true Manning coefficients are then supposed to be known and are used to generate synthetic SWOT observations over the period 2002-2003. The impact of the assimilation system on the Niger Basin hydrological cycle is then
\end{abstract}

quantified. The optimization of the Manning coefficient using the EKF (extended Kalman filter) algorithm over an 18month period led to a significant improvement of the river water levels. The relative bias of the water level is globally improved (a $30 \%$ reduction). The relative bias of the Manning coefficient is also reduced ( $40 \%$ reduction) and it converges towards an optimal value. Discharge is also improved by the assimilation, but to a lesser extent than for the water levels $(7 \%)$. Moreover, the method allows for a better simulation of the occurrence and intensity of flood events in the inner delta and shows skill in simulating the maxima and minima of water storage anomalies, especially in the groundwater and the aquifer reservoirs. The application of the assimilation method in the framework of an observing system simulation experiment allows evaluating the skill of the EKF algorithm to improve hydrological model parameters and to demonstrate SWOT's promising potential for global hydrology issues. However, further studies (e.g., considering multiple error sources and the difference between synthetic and real observations) are needed to achieve the evaluation of the method.

\section{Introduction}

The impact of climate variability on land water storage is becoming an increasingly crucial issue for the development of future water resource management strategies. In order to investigate this impact, continental hydrologic systems (CHSs) can be used to simulate water dynamics above and 
below the land surface as a response to environmental forcing. CHSs are generally made of a land surface model (LSM) which computes the water and energy budget at the surfaceatmosphere interface, coupled with a river routing model (RRM) which distributes the runoff to the river and the soil storage components. At regional or global scales, the realistic representation of major surface hydrologic and hydrodynamic processes is very challenging and requires the use of computationally efficient, easily parameterized, comparatively simple and physically based routing methodologies. However, land surface hydrologic processes are highly heterogeneous in space and time and are therefore difficult to parameterize given the huge dimensions of atmospheric general circulation model (AGCM) grid areas. Observational data describing the water dynamics and storage variations are required to evaluate CHS-simulated diagnostics, and to calibrate these models. In situ data have been extensively used, but they are limited by their temporal and spatial coverage. In addition to the information provided by in situ measurements, satellite remote sensing instruments have been developed and are continually improved. These instruments generally provide a large spatial coverage which is more appropriate for global applications, especially in areas where in situ data are scarce. Such areas are generally sparsely inhabited, with reduced infrastructures and possible geopolitical issues, such as large portions of the African continent or part of the Arctic (Alsdorf et al., 2007). Applications using satellite remote sensing techniques lead to many promising perspectives for improving the observation of land surface and hydrological variables and processes.

Hydrological models require information about continental water dynamics and storage variations above and below the surface for calibration and evaluation of the simulated water budget. To this end, diverse types of monitoring data are needed. In situ discharge data, for example, give information of 1 spatial dimension, which quantifies water fluxes in a specific river channel, but do not give any direct information about runoff or lateral inflow. Yet, hydrologically complex areas, such as wetlands and floodplains which are processes of three spatial dimensions, cannot be adequately resolved using observations of 1 spatial dimension (Alsdorf et al., 2007). Spatially distributed observations are required, such as those provided by satellites which give 2-dimensional information about surface water dynamics. Recently, efforts have been made to build global maps of floodplain variability and extent, providing an additional metric for CHS evaluation (Papa et al., 2010). Nadir altimetry has also constituted a valuable progress for the monitoring of surface water dynamics and elevation (TOPEX/Poseidon, Envisat, Jason 1 and 2; Baup et al., 2007; Santos Da Silva et al., 2012).

Although useful, current satellite altimetry spatial resolution does not resolve small-scale land water dynamics thereby limiting our understanding of large-scale hydrologic and hydrodynamic processes. The future NASA-CNESCSA Surface Water and Ocean Topography (SWOT) satel- lite mission will be launched in 2020 and will deliver maps of water surface elevation (WSE), slope and extent with an unprecedented resolution of $100 \mathrm{~m}$.

For continental hydrology, the SWOT mission has the potential to help deal with critical issues, such as monitoring transboundary basins and the development of management strategies in a changing world. It is necessary to determine how the SWOT data can be used to improve hydrological simulations and to better predict continental water storage.

Data assimilation (DA) has been shown to be a promising technique for improving river modeling (Andreadis et al., 2007; Durand et al., 2010; Biancamaria et al., 2011; Yoon et al., 2012). Commonly used in operational meteorology and oceanography, DA combines data coming from various sources, such as numerical models or observations, while taking into account measurement errors and model uncertainties for a better description and prediction of the system. However, these methods are not yet extensively used in hydrology and related works are rare, especially for large-scale applications. Drusch et al. (2009) used observations of $2 \mathrm{~m}$ air temperature and soil moisture to evaluate a Kalman filterbased soil moisture analysis system and its impact on the operational ECMWF (European Centre for Medium-Range Weather Forecasts)-integrated forecast system. They showed that the impact of EKF on the forecast skill of the operational weather forecast model was neutral in terms of forecast score but gave the promising possibility to better constrain the soil water content with more accurate soil moisture estimates. Pereira-Cardenal et al. (2011) investigated the potential of using Envisat water levels observations in a real time or nearreal time by applying an ensemble Kalman filter in order to update semidistributed hydrological model state variables. The method was applied to the Syr Darya River basin, a complex mountainous region covering approximately $7000 \mathrm{~km}^{2}$. They showed that data assimilation allowed for a better realtime estimation of reservoir levels over the region. However, because of the state updating procedure used in this study, which consisted in adding or abstracting water from reservoirs, the method is limited to medium-range forecasting. It is not suitable for long-term water resources scenario calculations, where mass balance has to be maintained. More recently, Michailovsky et al. (2013) used radar altimetry data from the Envisat mission for updating the storage of a routing model of the main reach of the Brahmaputra River driven by the outputs of a calibrated rainfall-runoff model showing the potential for the use of altimetric data in combination with hydrological models for flow modeling in large rivers.

However, in situ flow data were required for the calibration of the rainfall-runoff model which may still be a limitation in some areas with poor data availability such as the Niger River. Salamon and Feyen (2009) used the residual resampling particle filter to assess parameter, precipitation and predictive uncertainty in the distributed rainfall-runoff hydrological model LISFLOOD for the Meuse catchment using discharge measurements. They showed that the equifi- 


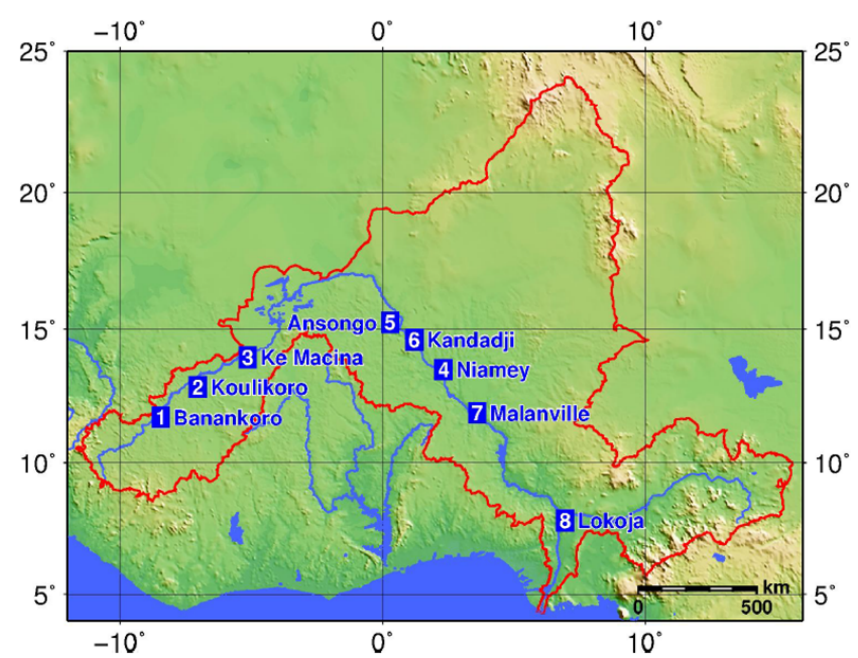

Figure 1. The Niger River basin. The spatial resolution is $0.5^{\circ} \times 0.5^{\circ}$. The red contour marks the boundary of the Niger Basin. The squares correspond to the following locations: (1) Banankoro, (2) Koulikoro, (3) Ke Macina, (4) Niamey, (5) Ansongo, (6) Kandadji, (7) Malanville and (8) Lokoja. Terrain elevations come from ETOPO2 (m).

nality hypothesis (several different parameter sets can lead to a good estimation of the discharge) was a limitation to the correction of a distributed hydrological parameter even in a physically based hydrologic model. Moreover, they emphasized the strong effect of rainfall uncertainties on the analysis. Finally, the results showed that accounting for parameter uncertainty only during a calibration phase was not sufficient to properly predict uncertainty, limiting the application of the method for hydrologic forecasting over longer time periods. The aforementioned applications of DA in hydrological modeling have shown the potential of using remote sensing data in order to improve the model states or the parameters. However, they also showed the limitations due to the generally low spatial and temporal resolutions of these data sets. Hydrological model uncertainties can come from several sources, such as model structure, input parameters or input data (mostly precipitation), leading to the development of different DA methodologies. Depending on the study, DA either aims at optimizing the model input parameters or at directly correcting the model state (generally done in operational forecast applications for example). The current study investigates benefits of assimilating SWOT virtual water levels in order to improve input parameters of a largescale hydrological model within the context of a prelaunch study. The domain study area is the transboundary Niger Basin (Fig. 1) which crosses a large part of the Sahel and is a critical source of water in this semiarid region. The West African region is also characterized by an increasing population, putting larger pressure on the already limited freshwater resources. The hydrology of this basin is modulated by the West African monsoon (WAM) seasonal and interannual variability which is characterized by extreme events such as droughts and floods which can have dramatic impacts on society and the regional economy. However, the lack of field measurements limits the understanding of the salient hydrological processes in the Niger Basin. For these reasons, it is an ideal test bed for studying global hydrological issues. In a previous study, a Niger Basin hydrological model application was set up using the ISBA (Interaction Sol-AtmosphereBiosphere)-TRIP (Total Runoff Integrating Pathways) distributed hydrological model. Along with river routing, this model includes a flooding scheme and a linear unconfined aquifer reservoir (Pedinotti et al., 2012). The model parameters were estimated using geomorphologic relationships to characterize the river characteristics. The modeling evaluation showed that the model was able to reasonably reproduce the major hydrologic and hydrodynamic processes. The model outputs were compared to in situ discharge as well as satellite-derived flood extent, total continental water storage changes and river height changes. The importance of floodplains was also demonstrated, since they have a considerable impact on discharge downstream of the inland Niger Delta. The confined aquifer improves the recession law, i.e., the curve of the decreasing flow and the simulation of low flows. However, some model deficiencies remain which can be due to forcing or model uncertainties; among these sources of error are the uncertainties of TRIP hydrological parameters. Indeed, these distributed parameters are defined by empirical relationships using available observations which are adapted towards obtaining the best results over the entire globe. However, such relationships might not give the best results locally (for a particular basin). Studies showed that empirical equation does not work well even within one basin and significant errors can be found at subbasin or reach scales (e.g., Miller et al., 2014; Yamazaki et al., 2014). These relationships thus lead to nonnegligible errors which could be reduced using satellite data. Such data can potentially be used to estimate spatial parameters for each particular basin and then contribute to the development of a global database describing major river characteristics. Pedinotti et al. (2012) performed sensitivity tests to determine the main sources of uncertainty among the TRIP parameters. These tests have shown that the model was sensitive to modifications of some key river parameters (river height and depth as well as Manning coefficient) and that a good estimation of those parameters was required to optimize the simulation errors. The aim of the current study is to investigate how SWOT water level products can be used to optimize the Manning coefficient. Unlike river depth and width, which can be estimated through direct measurements, the Manning coefficient can be estimated only indirectly, using bathymetry and flow velocity measurements. Several studies have discussed the importance and difficulty of estimating the Manning coefficient (Chow et al., 1989; Bates and de Roo, 2000). The sensitivity of the Manning equation to several river parameters including the roughness coefficient was investigated by Pistocchi and Pen- 


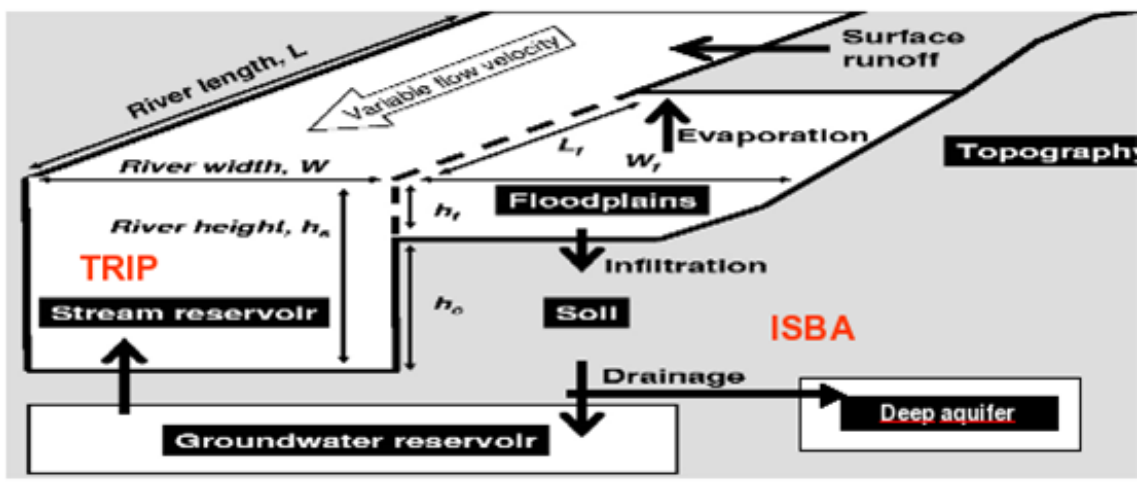

Figure 2. The TRIP model configuration in ISBA.

nington (2006). In addition to the concern about accurately estimating the Manning coefficient value, they highlighted the importance of considering its spatial distribution instead of a unique value as it is done in some hydrological models (Arora and Boer, 1999). Moreover, the Manning coefficient is often used as an adjustment variable for model calibration which can lead to additional errors (e.g., Biancamaria et al., 2009). Hunter et al. (2007) indicated that very frequently in models errors on topography and roughness dominate errors from equation approximation. The estimation of the Manning coefficient is thus considered in the literature as one of the major issues limiting the performance of hydrological models and, to the authors knowledge, there have been very few attempts to evaluate the potential of satellite data to correct it. Therefore, it was chosen as the main parameter to be investigated in the DA study presented in this study. Since SWOT observations are not yet available and to assess the usefulness of data assimilation, this study is carried out within the framework of an OSSE (observing system simulation experiment) using the TRIP model for the simulation of the Niger hydrodynamics. SWOT virtual measurements are produced using a reference ISBA-TRIP simulation. Here, it is assumed that modeling errors are only due to one key parameter which cannot be directly estimated via observational data: the Manning roughness coefficient (the other sources of modeling errors are not considered here, and the reasons will be explained in Sect. 4.1). The impact of the assimilation system on the Niger River model is then quantified. First, a brief presentation of the study domain and the model is made in Sect. 2. In this section, the Manning coefficient is also defined and its spatial distribution used for the true simulation is shown. Then, the production of the SWOT virtual water level is described in Sect. 3. The methodology used to build the assimilation scheme is explained, and the main variables of the assimilation problem are described in Sect. 4. Finally, the impact of the assimilation on the main hydrological variables of the Niger Basin is discussed in Sect. 5 .

\section{Study domain and model description}

\subsection{The Niger River basin}

Originating in the Guinean highlands within the Upper Guinea (Haute Guinée) and Forested Guinea (Guinée Forestière) regions located in the Fouta Djallon mountain range, the Niger River is the third longest river in Africa $(4200 \mathrm{~km})$, after the Nile and the Congo. Its outlet is located in Nigeria, discharging through a massive delta into the Gulf of Guinea. On its way through Mali, it crosses a vast floodplain region called the inland delta. The inland delta has an average surface area of $73000 \mathrm{~km}^{2}$, and it dissipates a significant proportion of the flow of the river through absorption and evaporation (it is estimated that about $40 \%$ of water is lost through the inland delta by evaporation and/or infiltration; Andersen et al., 2005). From the headwaters to the Niger Delta (taking into account the hydrologically active area), the basin has an average area of about 1.5 million $\mathrm{km}^{2}$. The Niger River is shared by nine countries and is the main source of water for about 100 million people living principally from agriculture and farming. During the 1970s and 1980s, West Africa faced extreme climate variations with extended drought conditions followed by floods; therefore, there is a need to better understand the functioning of this basin for water management purposes. The complexity of modeling the Niger Basin is mainly due to the fact that it crosses very different climatic zones, from the tropical humid Guinean coast where it generally rains every month of the year, to the desertic Saharan region. The main source of water over the basin is due to the WAM which is characterized by a marked annual cycle and significant interannual variability, leading to the succession of extreme events such as droughts and floods. In addition to modeling issues due to rainfall uncertainties, the representation of processes such as infiltration and evaporation from floodplains is also very important in modeling the Niger River. 

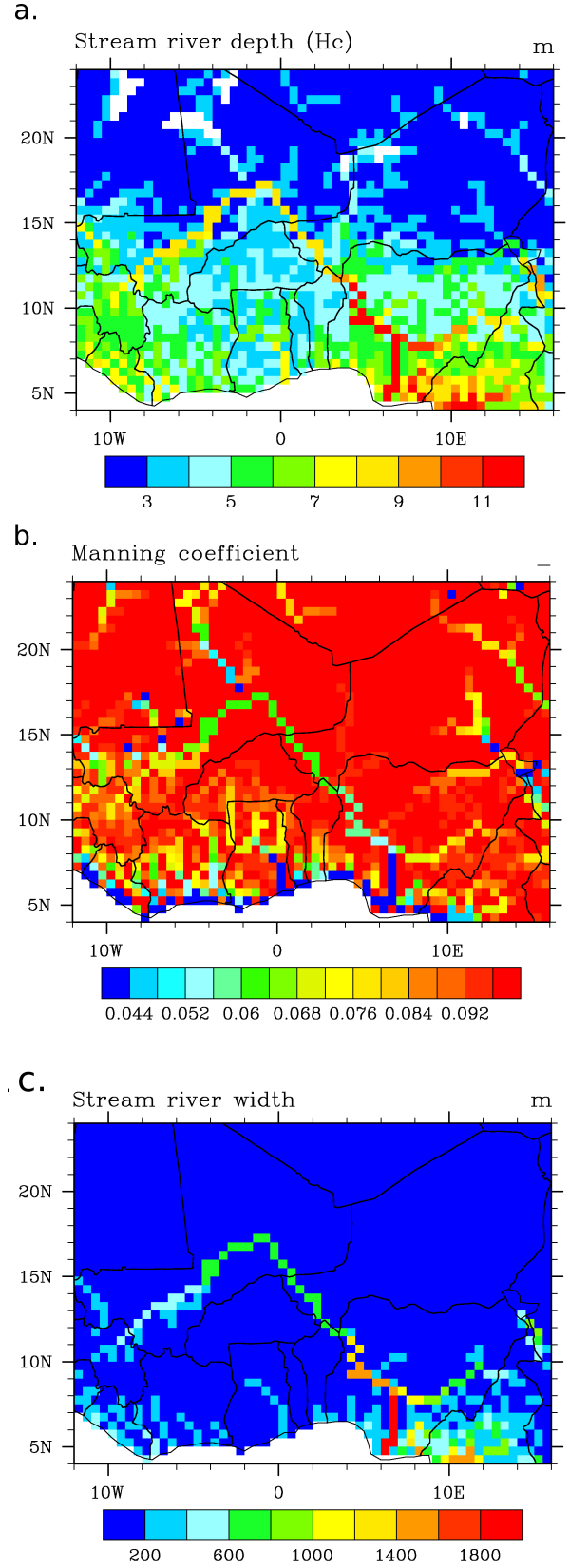

Figure 3. The spatial distribution of river depth (m) (a), Manning coefficient (b), and river width $(\mathrm{m})(\mathbf{c})$ parameters in ISBA-TRIP.

\subsection{Review of the ISBA-TRIP model}

ISBA is a state-of-the-art land surface model which calculates the time evolution of the surface energy and water budgets (Noilhan and Planton, 1989). It represents the natural land surface component of the SURface-EXternalized (SURFEX) coupling platform at Météo-France (Masson et al., 2013). In the current study, we use the three-layer forcerestore soil hydrology option (Boone et al., 1999). The options are also activated for a comprehensive representation of subgrid hydrology in order to account for the heterogeneity of precipitation, topography and vegetation in each grid cell. A TOPMODEL approach (Beven and Kirkby, 1979) has been used to simulate a saturated fraction, $f_{\text {sat }}$, over which precipitation is entirely converted into surface runoff (Decharme et al., 2006). Infiltration is computed via two subgrid exponential distributions of rainfall intensity and soil maximum infiltration capacity (Decharme and Douville, 2006). The TRIP original RRM was developed by Oki and Sud (1998) at University of Tokyo. It was first used at MétéoFrance to convert the model simulated runoff into river discharge using a global river channel network at a $1^{\circ}$ resolution. More recently, a $0.5^{\circ}$ resolution global river network has been developed which is used for this study. The TRIP schematic concept is presented in Fig. 2 and more details can be found in Pedinotti et al. (2012). The ISBATRIP CHS was recently improved to take into account a simple groundwater reservoir, which can be seen as a simple soil-water storage, and a variable stream flow velocity computed via the Manning equation (Decharme et al., 2010). In addition, ISBA-TRIP includes a two-way flood scheme in which a flooded fraction of the grid cell can be determined (Decharme et al., 2008, 2011). The flood dynamics are described through the daily coupling between the ISBA land surface model and TRIP RRM, including a prognostic flood reservoir. This reservoir fills when the river height exceeds the critical river bank full height (Fig. 3a), $h_{\mathrm{c}}(\mathrm{m})$. The flood interacts with the soil hydrology through infiltration, with the overlying atmosphere through precipitation interception and through free-water-surface evaporation. For the Niger application, Pedinotti et al. (2012) added a simple, linear, confined aquifer reservoir to account for the long-term water storage in deep and more or less confined aquifers. This reservoir was built on the example of the groundwater reservoir, but with a significantly longer time-delay factor. The confined aquifer is supplied by a fraction $(1-\alpha)$ of the drainage from ISBA, the remaining fraction $(\alpha)$ going to the groundwater reservoir.

\subsection{TRIP specific parameters}

The Manning coefficient characterizes the roughness so that it modulates the surface water velocity and thus water levels and discharge, via the Manning formula. However, it is difficult to estimate via in situ measurements or remote sensing techniques. In ISBA-TRIP, the Manning friction coefficient, $n_{\text {riv }}$, varies linearly and proportionally to the river width, $W$ (m), from 0.04 near the river mouth to 0.1 (Decharme et al., 2011) in the upstream grid cells (Fig. 3b):

$n_{\text {riv }}=n_{\min }+\left(n_{\max }-n_{\min }\right)\left(\frac{W_{\text {mouth }}-W}{W_{\text {mouth }}-W_{\min }}\right)$,

where $n_{\text {riv }}$ represents the grid cell average Manning coefficient, $n_{\max }$ and $n_{\min }$ the maximum and minimum values of the Manning friction coefficient (equal to 0.1 and 0.04 , re- 
spectively), $W_{\min }(\mathrm{m})$ the minimum river width value and $W_{\text {mouth }}(\mathrm{m})$ is the width of the mouth in each basin of the TRIP network ( $W_{\text {mouth }}=2000$ for the Niger Basin). $W$ is an important parameter because it controls both the river flow speed and the floodplain dynamics. It is computed over the entire TRIP network via an empirical mathematical formulation that describes a simple geomorphological relationship between $W$ and the mean annual discharge at each river cross section (Knighton, 1998; Arora and Boer, 1999; Decharme et al., 2011):

$W=\max \left(30, \beta \times Q_{\mathrm{yr}}^{1 / 2}\right)$,

where $Q_{\mathrm{yr}}\left(\mathrm{m}^{3} \mathrm{~s}^{-1}\right)$ is the annual mean discharge in each grid cell estimated using the global runoff database from Cogley (1979). As discussed in Decharme et al. (2011), the $\beta$ coefficient can vary drastically from one basin to another. $\beta$ is equal to 20 for the branch of the river going from the river mouth $\left(5^{\circ} \mathrm{N}\right)$ to $12^{\circ} \mathrm{N}$ and is fixed to 10 for the remaining river branch. The spatial distribution of the river width is shown in Fig. 3c. Another critical parameter is the riverbankfull critical height, $h_{\mathrm{c}}$, which is computed according to the river width via a simple power function (Decharme et al., 2011):

$h_{\mathrm{c}}=W^{1 / 3}$.

The spatial distribution of $h_{\mathrm{c}}$ is shown in Fig. 3a. These relationships are found to work well at the global scale but can lead to significant errors for a specific basin at the regional scale (see the sensitivity tests in Pedinotti et al., 2012). Indeed, the assumption that the river width is proportional to the annual mean discharge can lead to significant errors in flooded areas where the river bed enlarges but the discharge is reduced through the flooding process. Moreover, it is assumed that the Manning coefficient is only dependent on the river width while other factors should be considered, such as the presence of vegetation, debris, soil type, etc. Finally, these parameters are defined as constant in time, which is a significant assumption, especially in a region with a marked seasonal climate variability such as the Niger Basin. Remote sensing opens the possibility of estimating the river width by direct measurements and the critical bank-full height by indirect algorithms (Pavelski and Smith, 2008; Yamazaki et al., 2014; Durand et al., 2008). However, the Manning coefficient will still be difficult to estimate even using remote sensing. This study focuses on finding a methodology to estimate this critical parameter via DA.

\section{Satellite observations}

The aim of this work is to estimate the potential benefits of using SWOT satellite measurements to provide spatially distributed estimates of the Manning coefficient over the Niger
River basin. This section describes this future satellite mission and how virtual SWOT observations have been generated in this study.

\subsection{The SWOT mission}

SWOT will provide high-resolution images of water surface elevations over the oceans and continental surface water bodies. It will therefore observe continental surface waters at an unprecedented resolution, providing information for a better understanding of surface water dynamics and storage variations. The mission is currently planned to be launched around 2020.

The satellite main payload will be the Ka-band Radar Interferometer (KaRIN), a wide swath SAR (synthetic aperture radar) interferometer. KaRIN will have two antennas separated by a $10 \mathrm{~m}$ boom, which will observe two ground swaths of $60 \mathrm{~km}$ on each side of the satellite nadir, separated by a $20 \mathrm{~km}$ gap. The intrinsic pixel resolution will vary from 60 (near range) to $10 \mathrm{~m}$ (far range) across track and will be at best around $5 \mathrm{~m}$ along track (however, this value is also dependent upon decorrelation time). Yet, for these intrinsic pixels, water elevation measurements have metric errors, which increase along the swath (depending on the look angle). To increase vertical accuracy, pixels have to be aggregated: over a $1 \mathrm{~km}^{2}$ area inside the river mask, water elevation has a $10 \mathrm{~cm}$ or lower error (Rodríguez, 2012). River slopes will be measured with a $1 \mathrm{~cm} \mathrm{~km}^{-1}$ resolution, after processing elevations over $10 \mathrm{~km}$ river reaches (Rodríguez, 2012). SWOT will be able to observe rivers wider than $100 \mathrm{~m}$ (mission requirement) and should be able to observe rivers wider than $50 \mathrm{~m}$ (goal). The chosen orbit will be a low earth orbit with a $78^{\circ}$ inclination, in order to observe almost all of the continental surfaces (Rodríguez, 2012).

\subsection{Observing system simulation experiment (OSSE) and virtual SWOT data}

The OSSE framework consists in simulating data that would be observed by the future measurement platform using a numerical model, in order to use it as virtual observations for DA experiments. The main objective of an OSSE is to validate the DA method by using ideal conditions. It is assumed that the state of the system and the error statistics of the model and observations are known and correctly described, which is not the case in real conditions. This method is useful within the framework of the SWOT satellite mission preparation, since it allows a quantification of the satellite data contribution to improve large-scale river modeling (such as for the Niger Basin) before the launch of the satellite. First, a realistic modeling of the studied basin is needed for the OSSE. The model must be able to simulate the major hydrodynamic processes of the basin so that the simulated observations will reasonably represent the reality. The ISBA-TRIP setup evaluated in Pedinotti et al. (2012), with the inclusion 


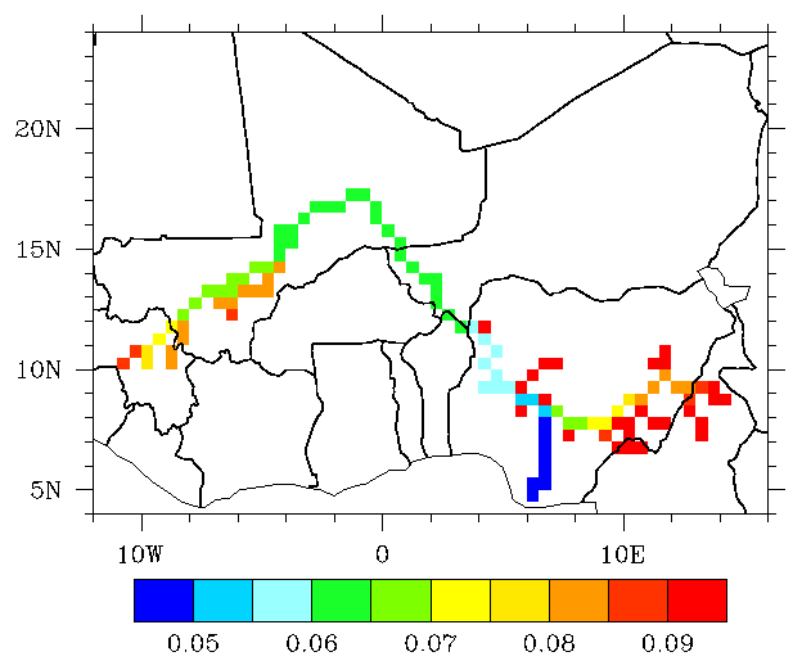

Figure 4. Distribution of the "true" Manning coefficient over the river. This distribution of Manning coefficients was used as an input parameter to run the reference ISBA-TRIP model.

of the flooding scheme and aquifer reservoir, is used to represent the true state of the hydrological system, also referred to as the reference simulation. For this so-called "truth", the model and its parameters are assumed to be perfect. An error is then added to this true state to build virtual observations. The background simulation results from the integration of the same model in a different configuration, for instance with a different set of parameters (also called perturbed or background parameters). It gives an a priori description of the system that is an approximation of the truth. In the present study focussed on parameter estimation, the purpose of the DA algorithm is to retrieve an optimal set of model parameters starting with the background parameters, by assimilating the virtual observations. It is important to note that in the present study, the error between the "true" Manning coefficients and the background Manning coefficients does not vary in time.

Within the framework of this SWOT-dedicated study, the true simulation is used to generate the SWOT observations, with the help of a relatively simple simulator developed by Biancamaria et al. (2011). Based on the prescribed orbit and swath, the simulator provides an ensemble of SWOT tracks and related dates. The SWOT tracks are provided for the orbital period and then repeated over the years 2002 and 2003 (assuming the satellite started its first orbit on 1 January 2002). The virtual data are the sum of the ISBA-TRIP water levels at the corresponding grid points and an instrumental error which is added to partially account for the SWOT observation errors (see Sect. 4.2.1 for details). A river mask for the Niger comprising grid cells with a river width above $200 \mathrm{~m}$ is defined as illustrated in Fig. 4, which displays the Manning coefficient for the unmasked 110 pixels. It should be noted that the SWOT satellite will not measure water depth but free-surface-water elevation. For DA applications in real conditions, the direct comparison between SWOT and ISBA-TRIP water levels will not be straightforward and will need further investigation. Indeed, the SWOT satellite measures free-surface-water elevation, which cannot be directly compared to the ISBA-TRIP outputs which are stream-water absolute depths in the river channel. The assimilation then requires finding a way to compare these two different variables in order to perform the DA. For example, they can be compared in terms of anomalies relative to a mean value over a long period of time instead of absolute water elevations. This method allows removing the bias due to different reference values of the level where the water elevation is zero. However, in the framework of an OSSE, the same model is used to generate the a priori and observed water levels and this issue can be evaded.

The 22-day repeat orbit and the $140 \mathrm{~km}$ swath used in this simulator allowed for a global coverage of the study domain within 22 days. Among the available orbits, two orbits have been preselected by the NASA-CNES project team, for various scientific and technical reasons (mainly to seek a compromise between both the hydrological and oceanographic scientific communities). These two orbits have the same repeat period, but different altitudes, meaning different subcycles. The repeat period corresponds to the minimum time taken by the satellite to fly over exactly the same ground location. Given the orbit parameters and earth's rotational speed, it requires a fixed number of satellite revolutions. For all of these revolutions, the part of the orbit that goes from north to south corresponds to the descending track and the one that goes from south to north corresponds to the ascending track. These ascending and descending tracks cross the Equator at different times during one repeat period. The difference between these crossing times for two adjacent ascending (or descending) tracks during a repeat period is the orbit subcycle. The $970 \mathrm{~km}$ altitude orbit has a 3-day subcycle, whereas the $873 \mathrm{~km}$ altitude orbit has a 1-day subcycle. These two orbits both have global coverage but with a different time and spatial spread of the satellite tracks during one repeat period. The 1-day subcycle orbit has two adjacent swaths every day, meaning that each river basin will be well sampled in few days, but then there will be no observations for several days (Fig. 5) with the risk of missing short-term events. The 3day subcycle orbit has two adjacent swaths every 3 days, on average, meaning ground tracks will be more regularly distributed in space and time. Yet, there will be no tracks close in time at any point during the cycle (Fig. 6). Thus, due to their spatial and temporal coverage over the domain, these two orbits present specific advantages and disadvantages that will be investigated within of the DA framework. The OSSE is run over 2 years starting from the beginning of the monsoon season, on 1 June 2002. During each SWOT 22-day repeat, there are about 53 satellite overpasses on the Niger Basin for the 3-day subcycle orbit and 50 for the 1-day subcycle orbit. 


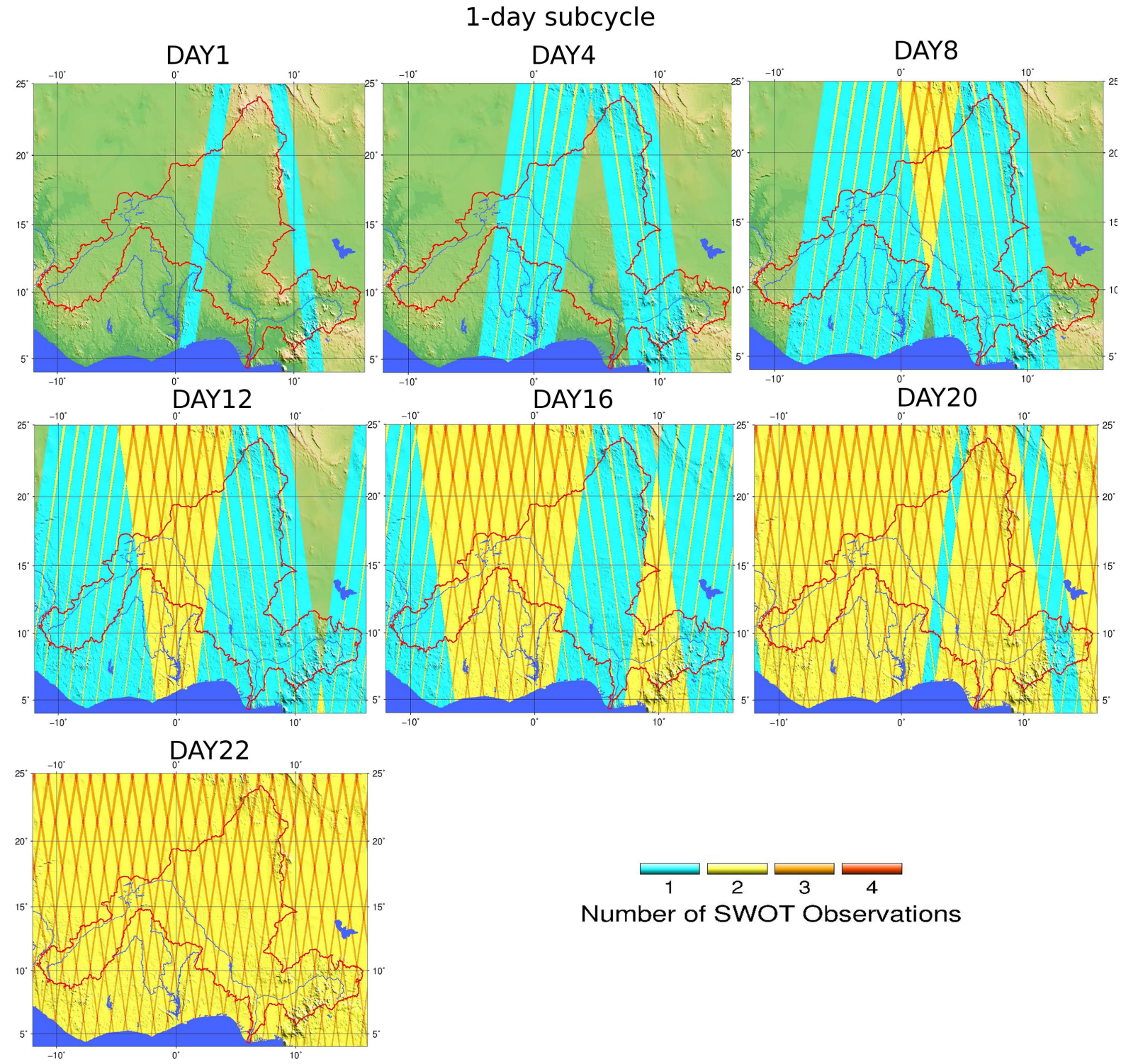

Figure 5. The 22-day repeat, $871 \mathrm{~km}$ altitude, 1-day subcycle orbit coverage, data issued from the SWOT data simulator.

\section{Data assimilation schemes}

\subsection{Choice of the control variable}

The goal of using assimilation in this study is to correct the TRIP routing input parameters which are associated with uncertainties. The contribution of such corrections is estimated by comparing model outputs (water level, discharge, water storage, etc.) with and without DA. Sensitivity tests in Pedinotti et al. (2012) determined the most sensitive TRIP parameters which impact the major hydrological processes of the Niger Basin. It was shown that a modification of $n_{\text {riv }}$ has a significant impact on the simulated hydrological variables over the Niger Basin which can be expected since the Manning coefficient is used for flow calculations in the river stream, via the Manning formula. Due to its close relationship with water levels and discharge, it is one of the most important empirical parameters in the field of hydrology and hydraulics. Thus, a good estimation of this coefficient in the river bed leads to a better reproduction of surface water dynamics. There is a tendency to regard the selection of the Manning coefficient as an arbitrary or intuitive process. Hydrodynamic modelers usually determine the value of the Manning coefficient manually, often using estimations based on visual interpretation of the land cover. The roughness can also be described by geomorphologic relationships, which are related to another parameter for which more information is known (river width for example). In ISBA-TRIP, $n_{\text {riv }}$ is assumed to vary linearly with $W$, from 0.04 near the river mouth to 0.10 in the upstream grid cells (Eq. 1). These geo- 


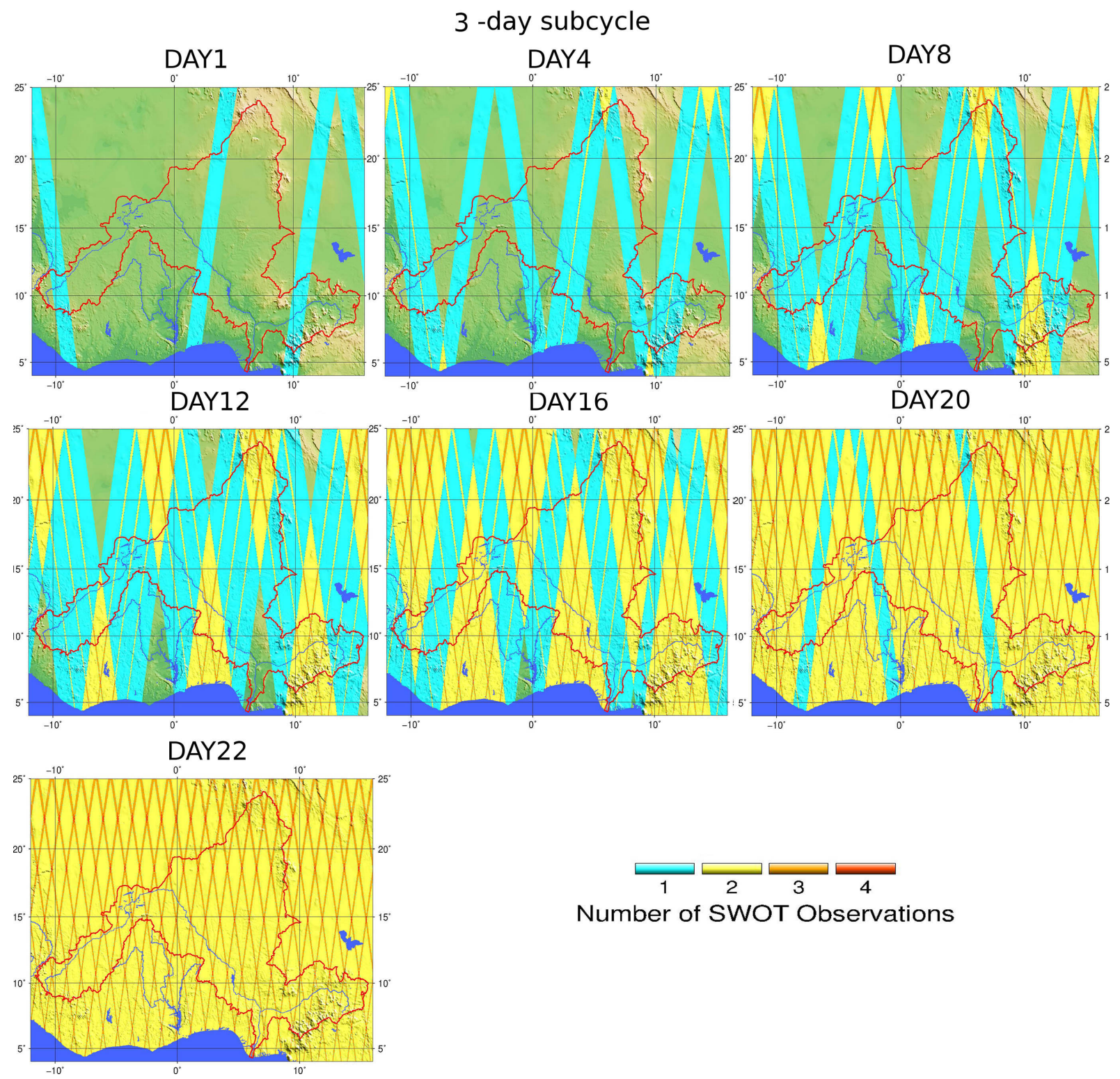

Figure 6. As in Fig. 5, except for a 22-day repeat, $970 \mathrm{~km}$ altitude, 3-day subcycle orbit average.

morphologic relationships are used to obtain the spatially distributed Manning coefficient which provides a "global" fit or best estimate. However, the accuracy of these relations can be very uncertain due to the significant heterogeneity of the river and land properties, especially in uncalibrated models. Both approaches can lead to significant errors over a large computational domain which is characterized by multiple land use/cover classes. Although progress in remote sensing will probably improve our estimates of the Manning coefficient (using the two aforementioned approaches), this parameter will not be estimated directly via remote sensing and therefore will remain dependent on the physical relevance of the geomorphologic relationships. Thus, DA appears to be an appealing option for estimating the Manning coefficient using remote sensing data. In reality, the temporal variability of the error on the Manning coefficient is related to the flow dynamics as the river bed morphology can be significantly modified by flood events. Even though this temporal variability is not accounted for in our OSSE framework, the DA analysis is performed sequentially over a 2-day time window which allows for a high variability of the correction on the Manning coefficient. It should be noted that in a real case study where sources of uncertainty are multiple (contrary to our OSSE framework where errors are only due to Manning coefficient perturbations), correcting the Manning coefficient could be interpreted as a way to account for other uncertainties (which are possibly characterized by errors with a higher temporal variability than that of the Manning coefficient). 


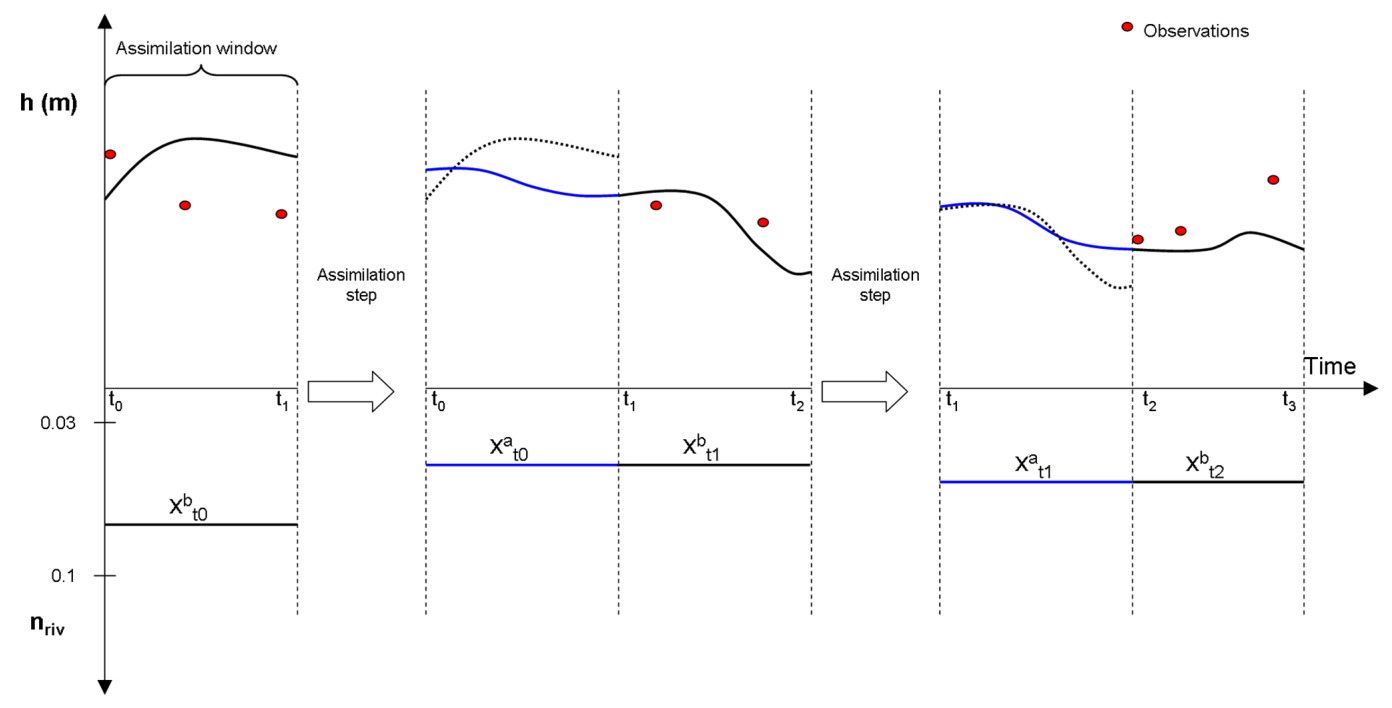

Figure 7. Schematic of the assimilation scheme used in this study. The black line represents the a priori or background trajectory and the blue line is the posterior trajectory after data assimilation. After the DA step, the a priori trajectory is represented by a dashed line to compare with the new trajectory.

The choice of the time window length could be revisited in further studies. However, a longer assimilation window also requires a bigger disc storage capacity and this must be considered when selecting the length of the assimilation window.

In the following section, along-track virtual SWOT data over 2 days are assimilated to correct the Manning coefficient for the unmasked $n_{t}=110$ ISBA-TRIP grid points. For each analysis at time $t$ (also called cycle), the control vector is thus a vector of 110 elements noted $\boldsymbol{x}_{t}$. The framework of the OSSE does not guarantee the physical representativeness of the modeled values, specifically because of the lack of monitoring data. Here, the values have therefore simply been bounded to be within a reasonable range (based on rivers similar to the Niger and the scale of TRIP).

\subsection{The extended Kalman filter (EKF)}

The assimilation algorithm used for the calculation of the analysis is the EKF, which is presented in this section within the framework of parameter optimization. The true Manning coefficients (known in the framework on an OSSE but unknown in reality) are gathered in the vector $\boldsymbol{x}_{t}^{\text {true }}$ of size $n_{t}$. The vector of the a priori parameters $x_{t}^{\mathrm{b}}$ for the hydrological models is prescribed by geomorphologic relationships which induce an error $\epsilon_{t}^{\mathrm{b}}=\boldsymbol{x}_{t}^{\text {true }}-\boldsymbol{x}_{t}^{\mathrm{b}}$ of which statistics are described in the background error covariance matrix B. Here, these statistics are assumed to be constant over the assimilation cycles and to follow a Gaussian distribution, centered on 0 with a standard deviation, $\sigma_{t}^{\mathrm{b}}$, of $20 \%$ of the average value of the Manning coefficient over the river.
The observation vector $\boldsymbol{y}_{t}^{0}$ of dimension $p_{t}$ contains all the SWOT observations collected during the 2-day assimilation window. The observation operator $H$ projects the control vector onto the observation space. This operator is nonlinear as it is the composition of the hydrological model $M$ and of a selection operator $S$ that simply extracts or interpolates the simulated water levels (over the whole gridded domain) at the observation points. Here $H=S o M$, where $S$ represents the SWOT simulator and $M$ is the integration of the hydrological model over the assimilation window. The relation $\mathbf{y}_{t}=H\left(\boldsymbol{x}_{t}\right)$ allows describing the true water level vector $\mathbf{y}_{t}^{\text {true }}$ at the observation points when $\boldsymbol{x}_{t}^{\text {true }}$ is used and the background hydrological water level vector $\mathbf{y}_{t}^{\mathrm{b}}$ at the observation points when $\boldsymbol{x}_{t}^{\mathrm{b}}$ is used. In OSSE, an observation error $\epsilon_{t}^{0}$ is added to $\boldsymbol{y}_{t}^{\text {true }}$ to account for instrumental and representativeness errors. The observation errors are assumed to be decorrelated in space and time, and the observation error standard deviation $\left(\sigma_{t}^{0}\right)^{2}$ is set equal to $\left(\sigma_{t}^{\mathrm{b}}\right)^{2}$. The observation error covariance matrix $\mathbf{R}_{t}$ is thus assumed to be diagonal. Further work should focus on a complete estimation of the observation error statistics in order to allow for alongtrack correlation of the instrumental errors (Lion, 2012).

The EKF analysis vector $\boldsymbol{x}_{t}^{\mathrm{a}}$ is defined as a correction to the background vector, where the the innovation vector $\boldsymbol{d}_{t}=$ $\boldsymbol{y}_{t}^{0}-\mathbf{H}_{t}\left(\boldsymbol{x}_{t}^{\mathrm{b}}\right)$ is multiplied by the gain matrix $\mathbf{K}_{t}$ :

$\boldsymbol{x}_{t}^{\mathrm{a}}=\boldsymbol{x}_{t}^{\mathrm{b}}+\mathbf{K}_{t} \boldsymbol{d}_{t}$,

where $\mathbf{K}_{t}$ reads

$\mathbf{K}_{t}=\mathbf{B}_{t} \mathbf{H}_{t}^{T}\left(\mathbf{H}_{t} \mathbf{B}_{t} \mathbf{H}_{t}^{T}+\mathbf{R}_{t}\right)^{-1}$,

where $\mathbf{H}_{t}$ is the tangent linear of $\mathbf{H}$ with respect to $\boldsymbol{x}_{t}$. The statistics of the analysis error $\epsilon_{t}^{\mathrm{a}}$ are determined by the 
Table 1. Principal variables, vectors and matrices used in the data assimilation of SWOT water levels (WL). The assimilation window length is $N$ days. The number $p$ of observed water levels during the assimilation window changes for each cycle.

\begin{tabular}{|c|c|c|}
\hline Symbol & Variable & Dimensions \\
\hline$y_{t}^{0}$ & $\begin{array}{l}\text { Observation vector, containing } \\
\text { the SWOT WL observations during } \\
\text { the } N \text { day assimilation window }\end{array}$ & $\begin{array}{l}p \text { (different for each } \\
\text { assimilation cycle) }\end{array}$ \\
\hline$x_{t}^{\mathrm{b}}$ & $\begin{array}{l}\text { Background vector, containing the } \\
\text { corrupted Manning coefficient } \\
\text { over the river mask }\end{array}$ & $n=110$ \\
\hline$x_{t}^{\mathrm{a}}$ & $\begin{array}{l}\text { Analysis vector, containing the } \\
\text { corrected values of the Manning } \\
\text { coefficient over the river mask }\end{array}$ & $n=110$ \\
\hline$M_{t}$ & ISBA-TRIP (nonlinear) & \\
\hline$H_{t}\left(\boldsymbol{x}_{t}^{\mathrm{b}}\right)$ & $\begin{array}{l}\text { ISBA-TRIP simulated water levels, } \\
\text { using } \boldsymbol{x}_{t}^{\mathrm{b}} \text { as an input parameter }\end{array}$ & $p$ \\
\hline $\mathbf{R}_{t}$ & $\begin{array}{l}\text { Observation error covariance matrix } \\
\text { (related to water levels) }\end{array}$ & $p \times p$ \\
\hline $\mathbf{B}_{t}$ & $\begin{array}{l}\text { Background error covariance matrix } \\
\text { (related to the Manning coefficient) }\end{array}$ & $n \times n$ \\
\hline$A_{t}$ & Analysis error covariance matrix & $n \times n$ \\
\hline $\mathbf{H}_{t}$ & $\begin{array}{l}\text { Jacobian matrix of } H \text { (sensitivity of } \\
\text { ISBA-TRIP water levels } \\
\text { to the Manning coefficient) }\end{array}$ & $n \times p$ \\
\hline $\mathbf{K}_{t}$ & Gain matrix & \\
\hline
\end{tabular}

analysis covariance matrix $\mathbf{A}_{t}=\left(\mathbf{I}-\mathbf{K}_{t} \mathbf{H}_{t}\right) \mathbf{B}_{t}$ (Bouttier and Courtier, 1999). The analysis vectors provide the corrected Manning coefficient values, which can then can be used to integrate the hydrological model and simulate the analyzed water levels over the whole domain. A schematic diagram of the assimilation process is shown in Fig. 7, and the key variables are represented in Eqs. (4) and (5) and listed in Table 1.

\subsection{Jacobian matrix calculation}

The EKF algorithm relies on the computation of a local approximation of the tangent linear of the observation operator that describes the relationship between the control vector and the observation space, with respect to the control vector. As the size of the control space is limited in this study, a finite difference scheme can be used to perform this approximation, in the vicinity of the background vector. Since the observation operator $H$ includes the model propagation, the calculation of the Jacobian matrix $\mathbf{H}_{t}$ requires the computation of $n_{t}$ independent integrations of the hydrological model with a perturbed element for each component of $\boldsymbol{x}_{t}$.

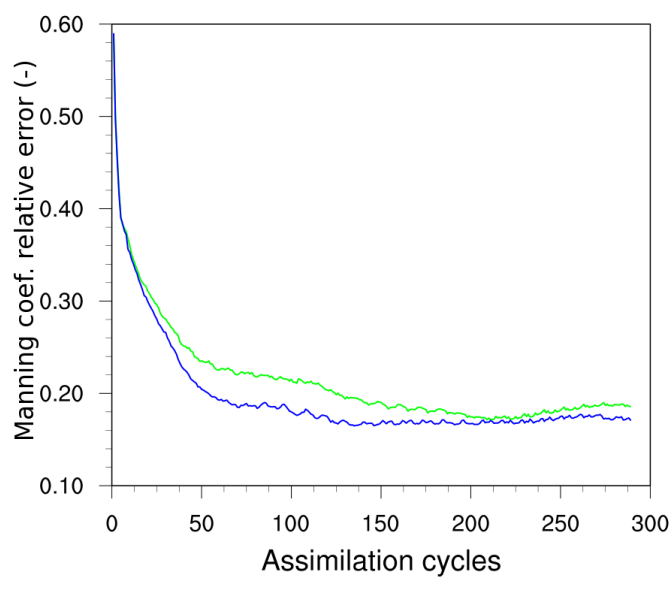

Figure 8. The Manning coefficient relative error averaged over the river versus time with a 1-day subcycle (green) and a 3-day subcycle (blue) orbit SWOT assimilation. The related error is calculated

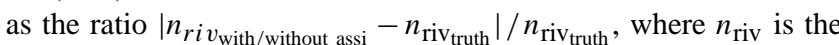
Manning coefficient.

$$
\begin{aligned}
\mathbf{H}_{t, i j}=\frac{\partial H}{\partial x}_{\left.\right|_{t, i j}} & =\frac{\mathbf{H}\left(\boldsymbol{x}_{t}+\Delta x\right)-\mathbf{H}\left(\boldsymbol{x}_{t}-\Delta x\right)_{i}}{\Delta x_{t, j}} \\
& =\frac{\Delta \boldsymbol{y}_{t, i}^{+}-\Delta \boldsymbol{y}_{t, i}^{-}}{\Delta \boldsymbol{x}_{t, j}^{+}+\Delta \boldsymbol{x}_{t, j}^{-}}
\end{aligned}
$$

In Eq. (6), $\mathbf{H}$ translates the variations of water levels at the observation points induced by the variation of Manning coefficients. $\Delta \boldsymbol{y}_{t, i}^{+}$and $\Delta \boldsymbol{y}_{t, i}^{-}$represent the water level variations at the gridded pixel "i" related to variations $\Delta x_{t, j}^{+}$and $\Delta \boldsymbol{x}_{t, j}^{-}$of the Manning coefficient at the gridded pixel " $\mathrm{j}$ ". A centered finite difference scheme was favored over a onesided scheme as it reduces noise on the evaluation of the local derivative. The computation of $\mathbf{H}_{t}$ thus requires $2 \times n_{t}$ integrations of ISBA-TRIP over the assimilation window using elementary perturbed Manning coefficients at the unmasked observation point. The computational cost of $\mathbf{H}$ could be optimized as only perturbations on Manning coefficients at the grid points located upstream of each observation point have an impact on water level at the observation point. In the present work, the $2 \times n_{t}$ integrations of ISBA-TRIP are achieved sequentially.

\section{Results}

The impact of DA on the hydrological processes is analyzed using the relative error. For any variable $v$, the relative error is expressed as

$\operatorname{err}_{v}=\left|\frac{v-v_{\text {truth }}}{v_{\text {truth }}}\right|$,

where $v_{\text {truth }}$ refers to the variable $v$ as described in the true simulation. 

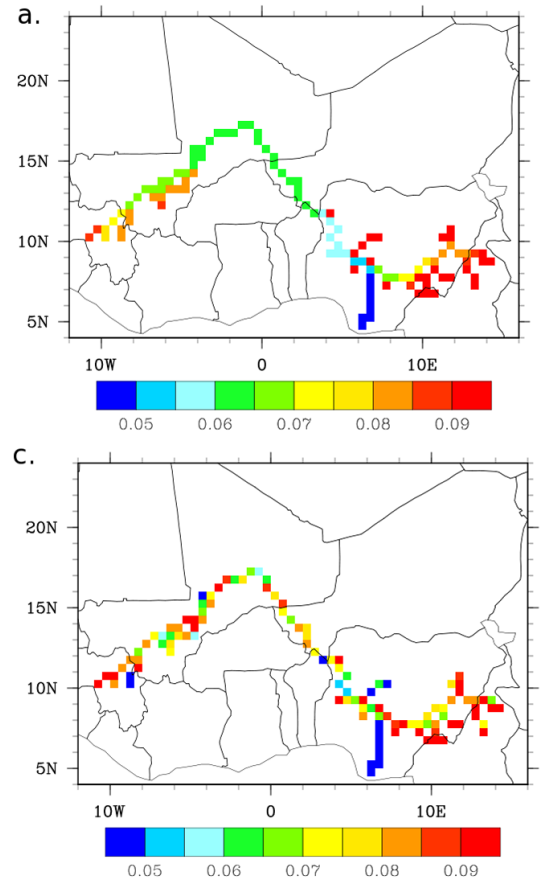
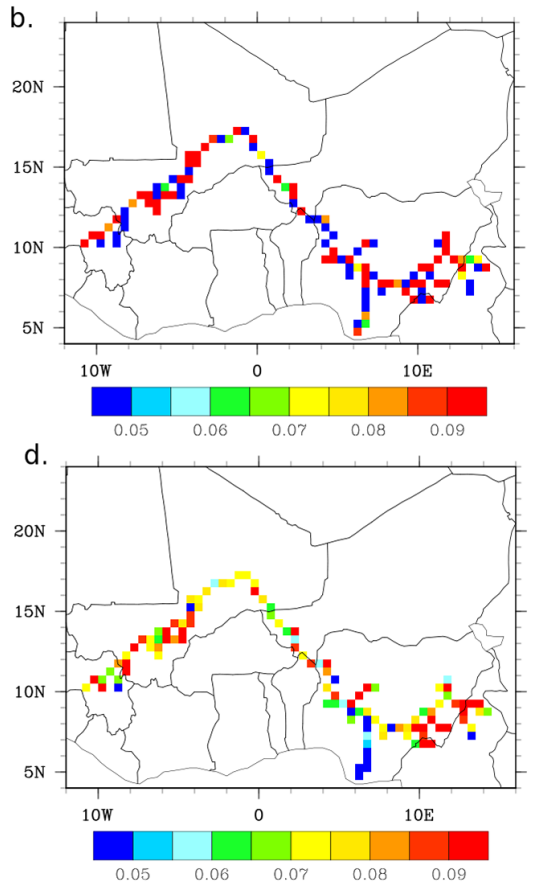

Figure 9. The Manning coefficient distribution (a) for the truth, (b) the background, (c) the 1-day subcycle assimilation at the end of the assimilation period (after 289 assimilation cycles in December 2003) and (d) the 3-day subcycle assimilation at the end of the assimilation period (after 289 assimilation cycles in December 2003).

\subsection{Impact of assimilation on Manning coefficient}

The truth simulation is made using Manning coefficients which are constant in time, meaning that there is no temporal variation of the error on the model parameters; thus, it is expected that the DA analysis leads to a constant value of the corrected Manning close to the "true" values.

However, since the Manning coefficient is spatially distributed, several spatial combinations of these parameters might resolve the assimilation problem which is generally referred to as the equifinality hypothesis. Figure 8 shows the Manning coefficient relative error (averaged over the river) time series for the two orbits. The average relative error of the Manning coefficient is significantly improved during the assimilation period and tends to converge to a stable value (about 0.19 for the 1-day subcycle orbit and 0.17 for the 3-day subcycle orbit), since the error is not significantly changed from January 2003 until the end of the assimilation experiment. The convergence towards the minimum value of the spatially averaged relative error to the true averaged Manning coefficient is slightly faster for the 3-day subcycle orbit than for the 1-day subcycle.

Figure 9 displays the spatial distribution of the Manning coefficient (a) for the truth, (b) the background simulation, (c) the 1-day subcycle assimilation at the end of the study period and (d) the 3-day assimilation at the end of the study period. The general patterns of the Manning coefficient distribution are recovered through the DA; especially, the extreme values of the background distribution are corrected. Also, we notice that the values downstream are better corrected than those upstream of the river, which can be expected since the downstream grid cells take advantage of the cumulated corrections upstream.

The Manning coefficient temporal evolution at the eight gage locations is shown in Fig. 10. It should be noted that in some places and for both subcycles, the "real" Manning coefficient value is only approached and not found through the assimilation cycles, which can be related to the equifinality problem. The 1-day subcycle and 3-day subcycle orbit assimilations converge to the same value in five locations out of eight. In Banankoro, Kandadji and Malanville, however, the coefficient values for the two orbits converge to different values. Banankoro is located upstream of the river, so this difference can be explained by the lack of data upstream of this location for obtaining a robust estimate of the Manning coefficient at this site. Also, the impact of the Manning coefficient on the simulation depends on the rain amount over the observed locations. According to the considered subcycle, the satellite will see different zones and a different number of observations corresponding to different rain events which can lead to the different values obtained for the optimal Manning coefficient in some locations. Also, a "jump" with a frequency of about 20 days is observed in every location and for the two subcycles and might be related to the orbit repetitivity. 

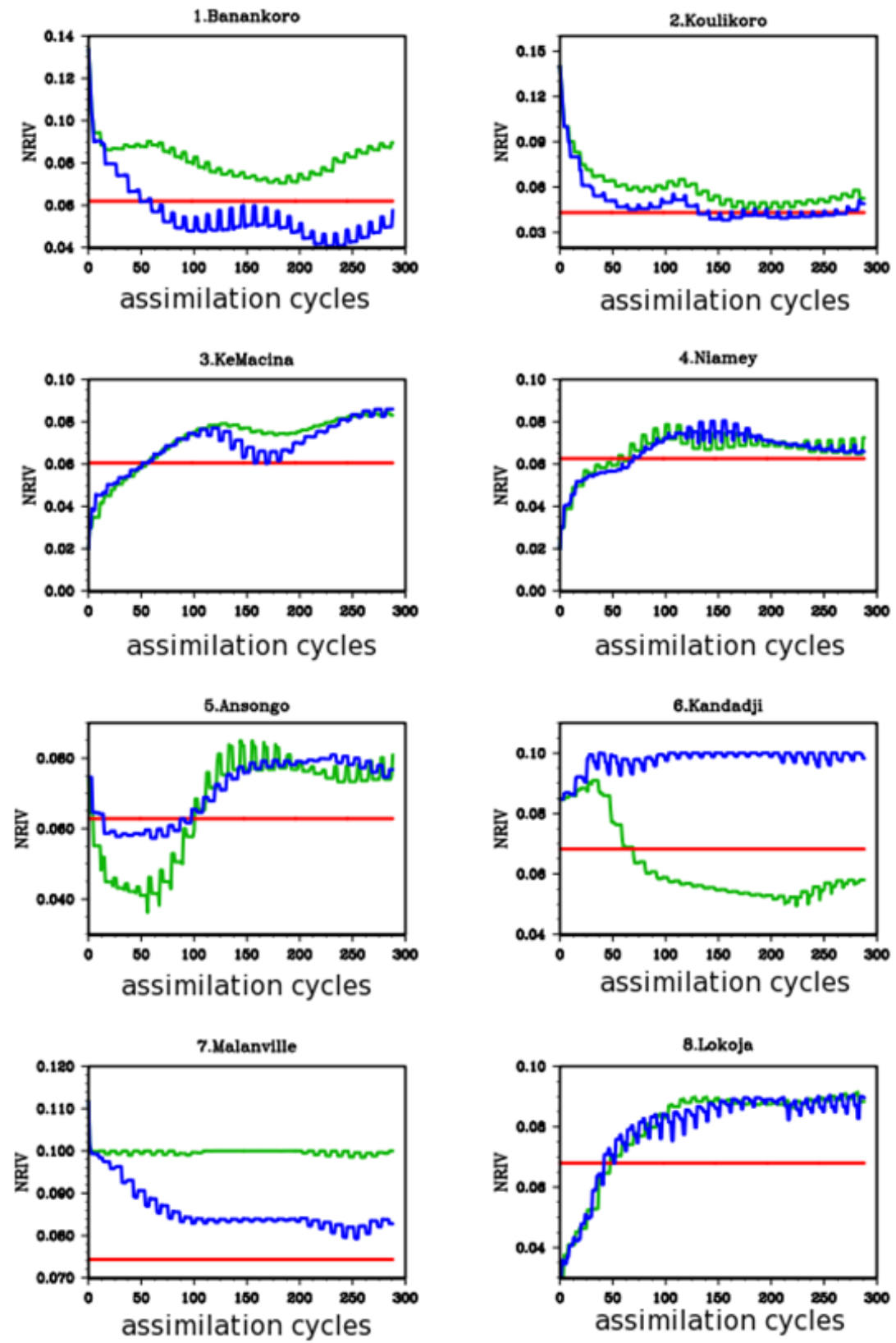

Figure 10. Manning coefficient versus assimilation cycle at eight locations (Fig. 1) for the 3-day subcycle (blue) and 1-day subcycle (green) orbits. The value of the true coefficient is in red.

Table 2. Water level relative error averaged over the river and at the location of the eight gages along the river (each gage is defined by its number specified inside the orange rectangles in Fig. 1). The relative error is calculated as the ratio $\left(h_{\text {with }} /\right.$ without assi $\left.-h_{\text {truth }}\right) / h_{\text {truth }}$, where $h$ is the water level (m); assi: assimilation, 3 and $1 \mathrm{~d} \mathrm{sbc:} \mathrm{3-} \mathrm{and} \mathrm{1-day} \mathrm{subcycles.}$

\begin{tabular}{llllllllll}
\hline $\begin{array}{l}\text { Location } \\
\text { no. }\end{array}$ & $\begin{array}{l}\text { River } \\
\text { mean }\end{array}$ & 1 & 2 & 3 & 4 & 5 & 6 & 7 & 8 \\
\hline No assi & 0.45 & 0.35 & 0.17 & 0.36 & 0.55 & 0.16 & 0.69 & 0.68 & 1.10 \\
3 d sbc & 0.12 & 0.09 & 0.25 & 0.11 & 0.17 & 0.12 & 0.12 & 0.10 & 0.09 \\
1 d sbc & 0.12 & 0.19 & 0.10 & 0.11 & 0.12 & 0.13 & 0.07 & 0.12 & 0.18 \\
\hline
\end{tabular}




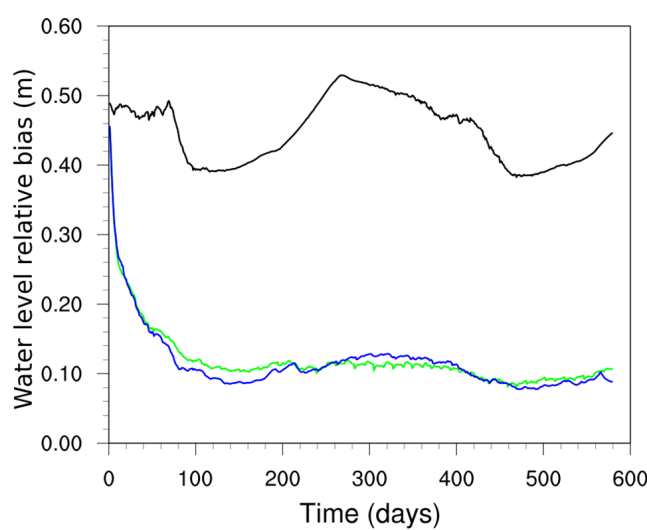

Figure 11. Water level relative error averaged over the river versus time with no assimilation (black), with 1-day subcycle (green) and 3-day subcycle (blue) orbit SWOT assimilations. The relative error is calculated as the ratio $\left|h_{\text {with/without assi }}-h_{\text {truth }}\right| / h_{\text {truth }}$, where $h$ is the water level (m).

\subsection{Impact of assimilation on water levels}

Table 2 gives the water level mean relative error computed with respect to the true water levels, first averaged over the entire river for the 2-year period and then at each of the eight observing stations shown in Fig. 1. Figures 11 and 12 display the water level relative error averaged over the river and at the eight observing stations as a function of time when (i) there is no assimilation (black curve), (ii) after a 1-day subcycle orbit SWOT-observation assimilation (green curve) and (iii) the 3-day subcycle orbit SWOT-observation assimilation (blue curve).

These results show that the DA analysis leads to a significant reduction of the water level relative error over the whole river (the averaged relative error is reduced by more than a factor of 3 with DA) and at the eight gages. In most of the eight locations, there is an improvement of several meters reaching up to $9 \mathrm{~m}$ at Lokoja (for an $8 \mathrm{~m}$ averaged river depth along the river). As for the Manning coefficient, a noise with a repeat period of 20 days is observed and can be directly related to the noise observed on the Manning coefficient. Also, even in the locations where the analyzed Manning coefficient differs for both subcycles, the same water levels are retrieved for both subcycles, which confirms the equifinality hypothesis.

A great improvement in the water level is achieved with the first assimilation cycles since the background Manning parameters and thus the background water levels initially differ significantly from the true parameter values and water levels. For the following cycles, as the background parameters are set equal to the analysis parameters, the sequential correction results in a convergence towards the optimal Manning coefficients leading to water levels that are coherent with the true water levels. The improvement is larger for stations that are located downstream of the river, possibly because of the cumulated corrections upstream of these stations. Moreover, the hypothesis of a linear relation between width and roughness means that the $20 \%$ standard deviation will lead to a larger absolute error on the roughness for wider rivers. These results are similar for both orbits as illustrated in Fig. 13, which shows the spatially distributed relative error of water levels averaged over the period from June 2002 to December 2003 for the run with (a) no assimilation, (b) a 3-day subcycle assimilation and (c) a 1-day subcycle assimilation. Without assimilation, the relative error over the river ranges between 0 and 1.2. With assimilation, more than $90 \%$ of the river pixels have a relative error smaller than 0.2 for both subcycles, and no pixel has a relative error higher than 0.5 .

\subsection{Impact of assimilation on river discharge}

Table 3 presents the discharge mean relative error computed with respect to the true discharge, first averaged over the entire river for the 2-year period and then at each of the eight observing stations shown in Fig. 1. Figures 14 and 15 display the discharge relative error averaged over the river and the discharge evolution at the eight observing stations as a function of time when (i) there is no assimilation (black curve), (ii) after a 1-day subcycle orbit SWOT-observation assimilation (green curve) and (iii) the 3-day subcycle orbit SWOTobservation assimilation (blue curve). The assimilation contributes to an improvement of the river discharge over the whole basin and at the eight locations, although this improvement is smaller than for water levels which can be expected since the Manning roughness is updated through level measurements. Discharge improvement, even if less significant than for water levels, can represent several hundreds of cubic meters per second globally and up to $3000 \mathrm{~m}^{3} \mathrm{~s}^{-1}$ in Lokoja. Discharge obtained after assimilation is somewhat "noisy" (as observed for water level) for both orbits during the wet season. This is likely due to a higher discharge sensitivity to Manning coefficient change during this period. Discharge is improved, in particular, at Lokoja, i.e., the location situated furthest downstream of the river, which is a promising result for coupled land-ocean applications since it shows that the RRM can provide a reasonable estimation of discharge at the river mouth. Similar to what was found for water levels, there is almost no discharge sensitivity to the considered orbit.

Figure 16 shows the spatially distributed relative error of discharge averaged over the period June 2002-December 2003 for the run without assimilation (a), 3-day subcycle assimilation (b) and 1-day subcycle assimilation (c). The discharge relative error is globally improved with better results over the inner delta for the 1-day subcycle orbit. Otherwise, there is no significant difference in results between the two orbits. Without assimilation, the relative error range over the river goes from 0 to 0.4 . With assimilation, all pixels have a relative error smaller than 0.2 , with $80 \%$ of them having errors of less than 0.1 . 

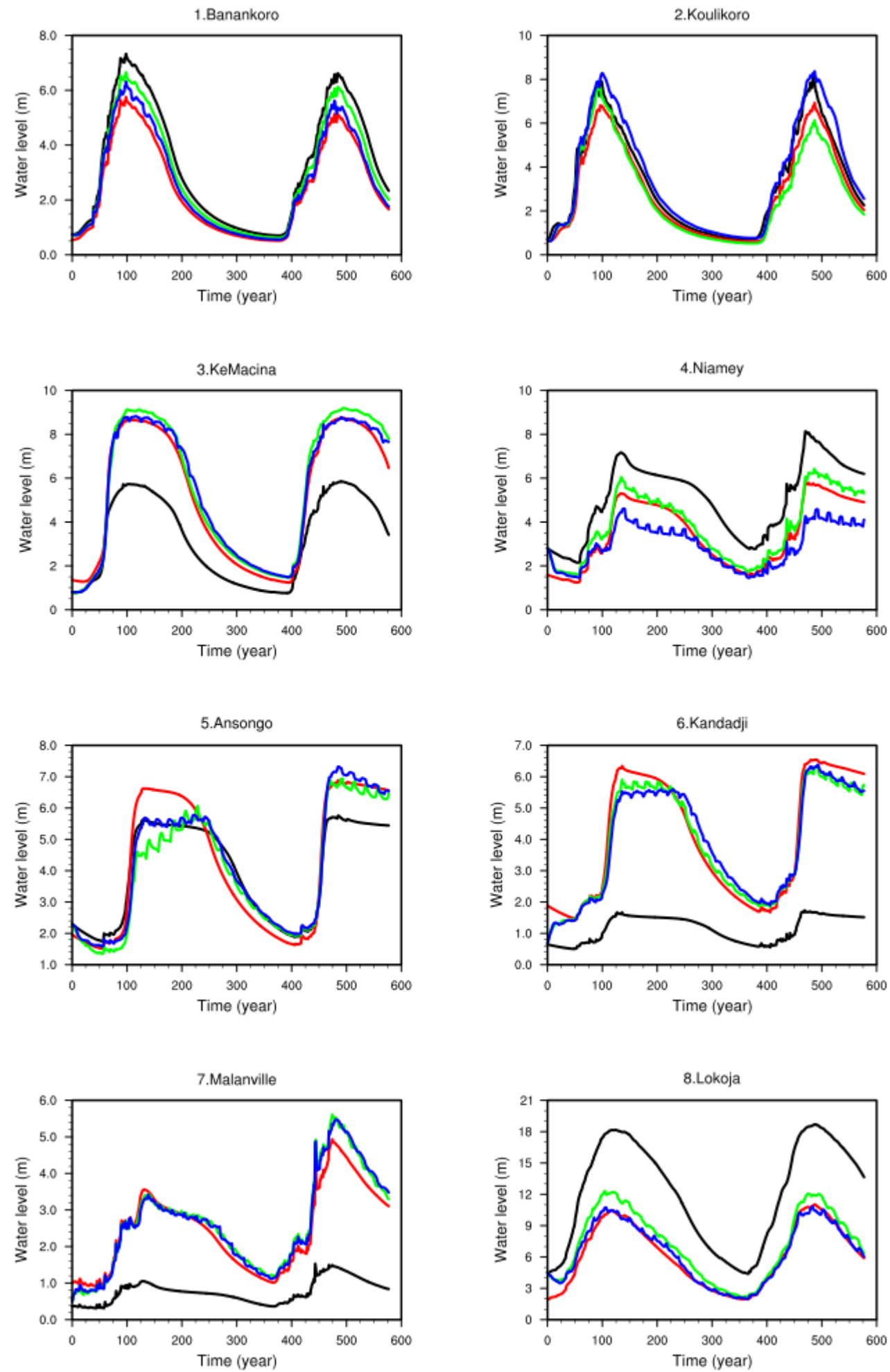

Figure 12. Time evolution of water levels at the eight locations shown in Fig. 1 for the "truth" (red curves), with no assimilation (black curves) and with assimilation of SWOT 1-day subcycle (green) and 3-day subcycle (blue) orbit observations. 
Table 3. Discharge relative error averaged over the river and at the location of the eight gages along the river (each gage is defined by its number specified inside the orange rectangles in Fig. 1). The relative error is calculated as the ratio $\left(q_{\text {with }} /\right.$ without assi $\left.-q_{\text {truth }}\right) / q_{\text {truth }}$, where $q$ is the discharge $\left(\mathrm{m}^{3} \mathrm{~s}^{-1}\right)$.

\begin{tabular}{llllllllll}
\hline $\begin{array}{l}\text { Location } \\
\text { no. }\end{array}$ & $\begin{array}{l}\text { River } \\
\text { mean }\end{array}$ & 1 & 2 & 3 & 4 & 5 & 6 & 7 & 8 \\
\hline No assi & 0.14 & 0.06 & 0.10 & 0.18 & 0.22 & 0.20 & 0.20 & 0.15 & 0.14 \\
$3 \mathrm{~d} \mathrm{sbc}$ & 0.08 & 0.04 & 0.04 & 0.11 & 0.14 & 0.14 & 0.14 & 0.09 & 0.06 \\
$1 \mathrm{~d} \mathrm{sbc}$ & 0.07 & 0.03 & 0.03 & 0.09 & 0.13 & 0.13 & 0.11 & 0.08 & 0.06 \\
\hline
\end{tabular}
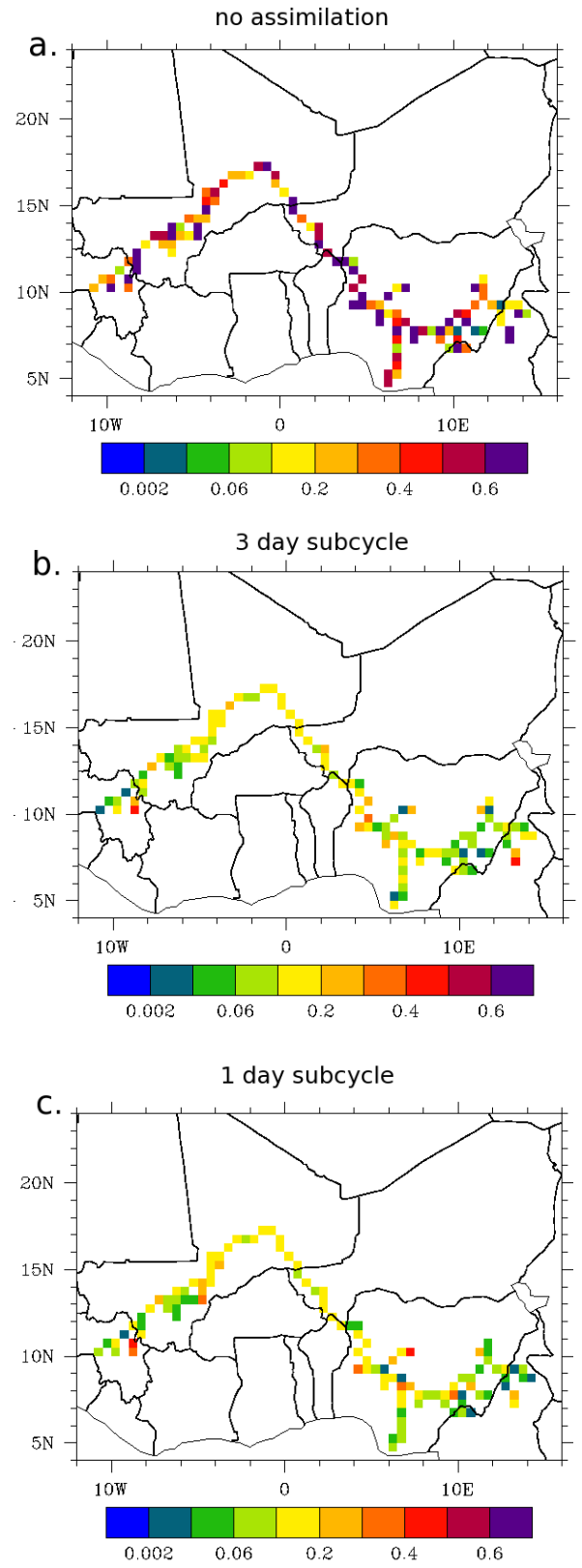

Figure 13. Relative error of water levels averaged over the period of assimilation.

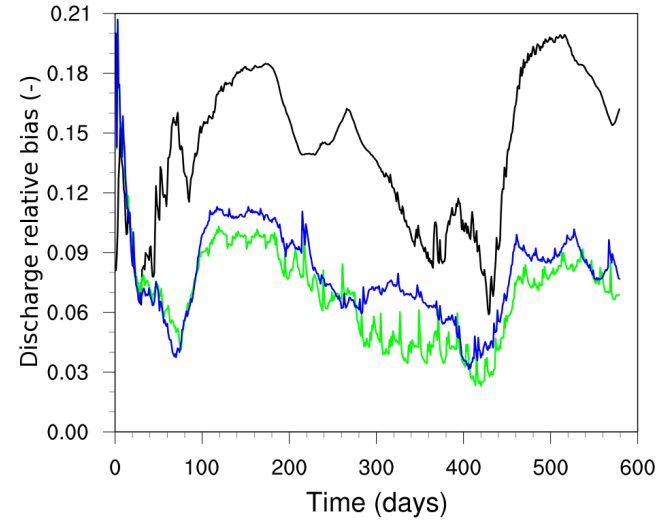

Figure 14. Discharge relative error averaged over the river versus time with no assimilation (black), with 1-day subcycle (orange) and 3-day subcycle (blue) orbit SWOT assimilations. The relative error is calculated as the ratio $\left(\mid q_{\text {with }} /\right.$ without assi $-q_{\text {truth }} \mid / q_{\text {truth }}$, where $q$ is the water level $\left(\mathrm{m}^{3} \mathrm{~s}^{-1}\right)$.

To better understand the relationship between the water levels and the discharge, the flooded fraction time series at two locations (Ke Macina and Lokoja) is shown in Fig. 17. In Ke Macina, there was no flooded fraction before the assimilation, while there was about $15-20 \%$ for the "truth". At this location, DA leads to a water level increase that generates flooding for both orbits, in agreement with the true run. The amplitude of the flooded fraction simulated with the assimilation for a 3-day subcycle is close to that of the true run while the flooded fraction simulated with assimilation for a 1 -day cycle is overestimated. This results because the water level and discharge results slightly overestimate the results from the true run for the 1-day orbit.

Another interesting case is observed in Lokoja, where the model simulates flooding in $25 \%$ of the grid area with no assimilation, which is not observed for the "truth". Here again, by reducing water levels, the assimilation considerably reduces the flooded fraction for the 1-day subcycle orbit and even prevents it from occurring for the 3-day subcycle orbit. No floods are modeled at the other sites for the truth, the run with no assimilation or the runs with assimilation, so these sites are not shown in Fig. 17. These results are valuable since they show that the use of DA corrects the flood 

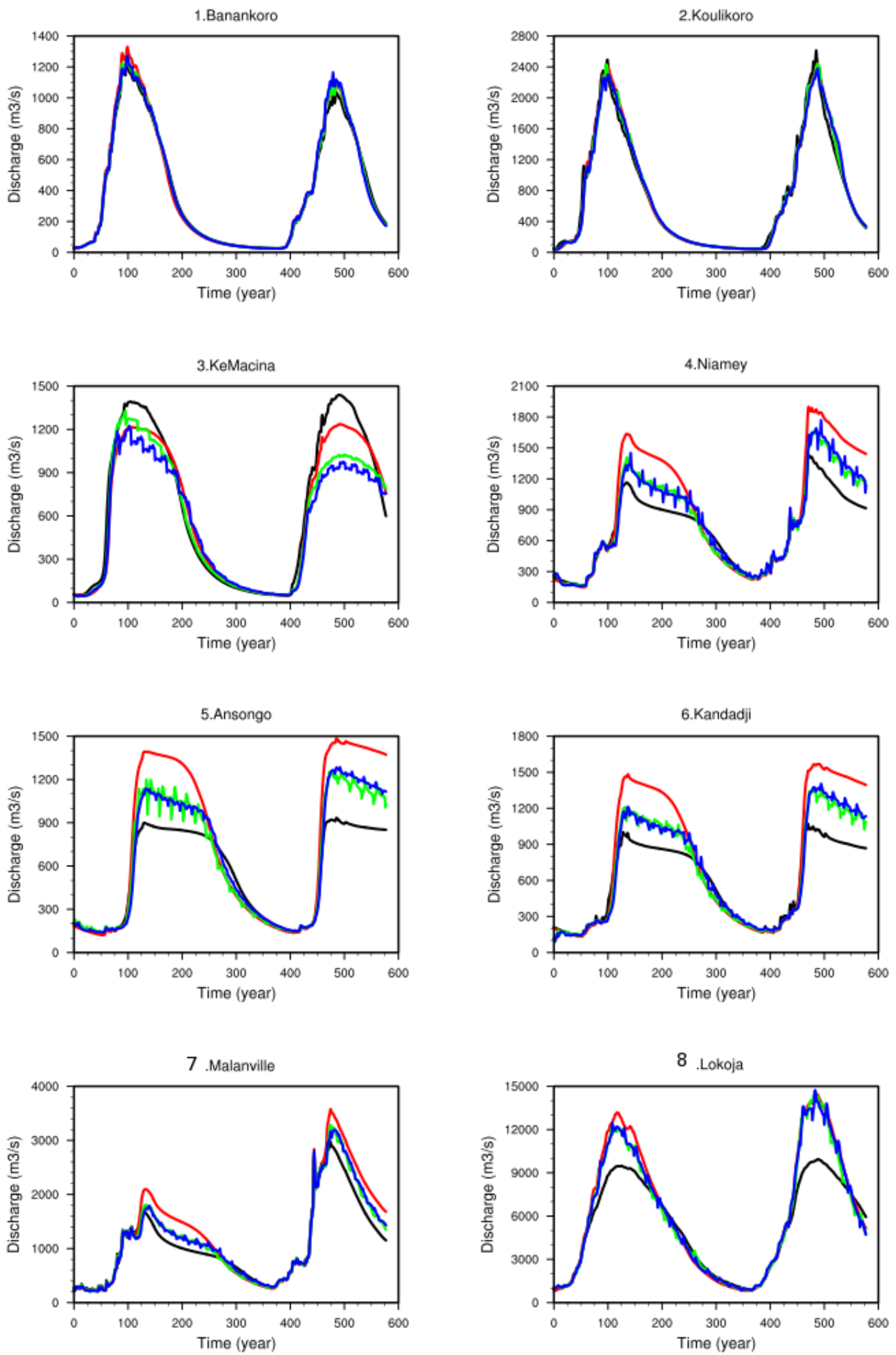

Figure 15. Time evolution of discharge at the location of the eight locations (Fig. 1) for the "truth" (red curves), with no assimilation (black curves) and with assimilation of SWOT 1-day subcycle (green) and 3-day subcycle (blue) orbit observations. 

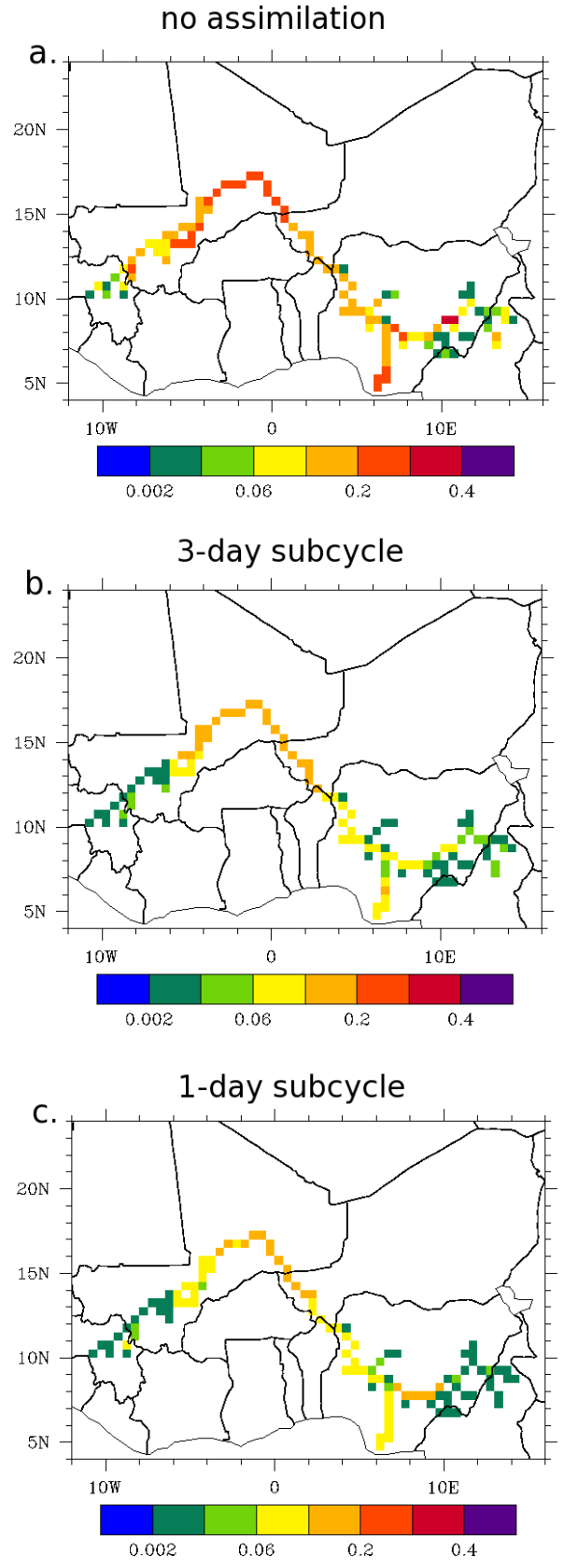

Figure 16. Relative error of discharge averaged over the period of assimilation.

prediction for two major sites of the Niger Basin. Indeed, Ke Macina is located just upstream to the entrance of the innerdelta region, while Lokoja is the last in situ station upstream of the river outlet. It should be noted that the discharge response to water level modification depends on whether or not there are floods. For example, at Ke Macina, during the monsoon period, the water level is increased via assimilation, which results in a better fit with the truth simulation and in a discharge decrease. This is coherent with the results of Pedinotti et al. (2012), in which the introduction of flood-
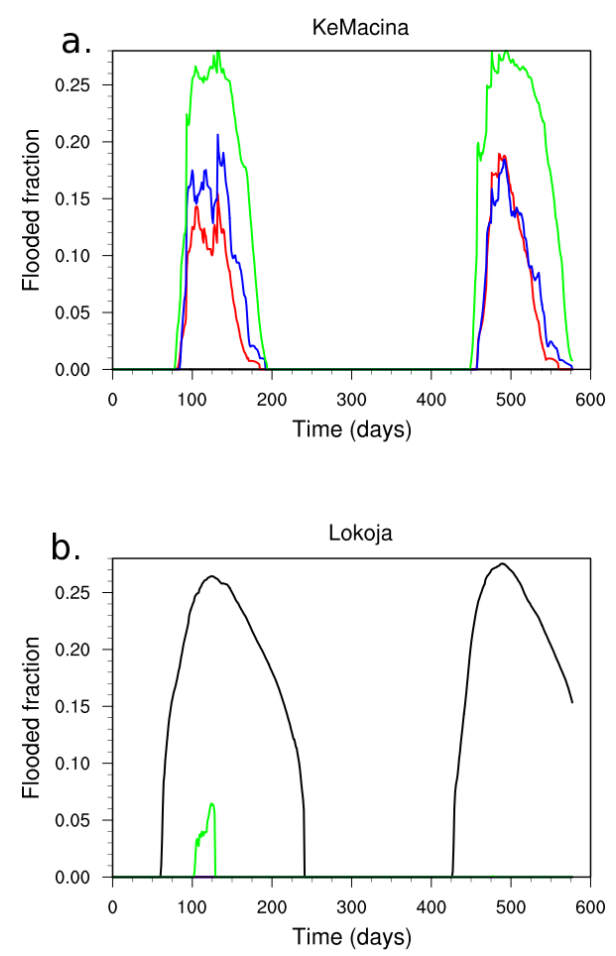

Figure 17. Flooded fraction versus time at Ke Macina and Lokoja, for the truth (red), with no assimilation (black), with assimilation for 3-day subcycles (blue) and 1-day subcycles (green). Note that in Lokoja, there is no flooded fraction represented for the truth and for the run with assimilation with a 3-day subcycle.

plains leads to a reduction of the discharge. However, in regions without floodplains, a water level increase leads to a discharge increase (see Kandadji for example).

The frequency of events as a function of the flooded fraction value (ratio of flooded area over pixel area) is shown in Fig. 18 for the truth (a), without assimilation (b), a 1day subcycle assimilation (c) and a 3-day subcycle assimilation (d). Only the pixels with a flooded fraction greater than $10 \%$ ( 0.1 on the horizontal axis) are considered. It is shown that without assimilation, the model does not simulate flooded fractions above 0.5 , which represents about $8 \%$ of the flood events for the truth simulation. Moreover, without assimilation, the model tends to overestimate the occurrence of smaller events. This is corrected by the assimilation, with a slight tendency to over-estimate flood intensity for the assimilation with the 3-day subcycle orbit, while the 1-day subcycle orbits leads to an excessive occurrence of flooded fractions contained in the [0.2-0.3] range. According to these results, DA allows for a better simulation of the water storage variations and leads to better estimation of flood event occurrence and intensity in the inner-delta area. 
a.

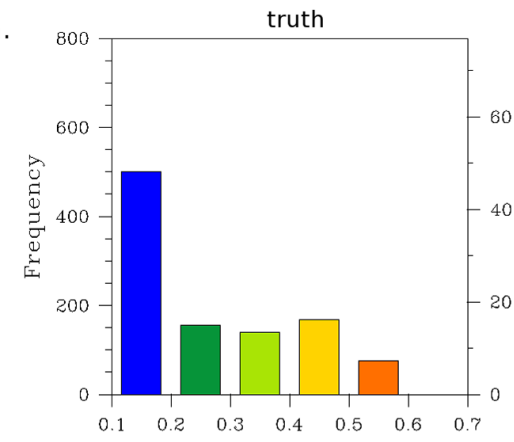

d.

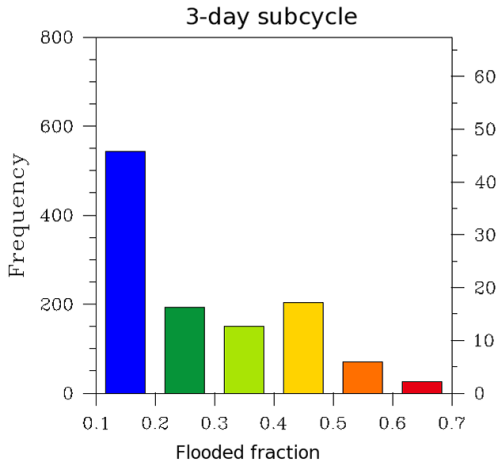

b.
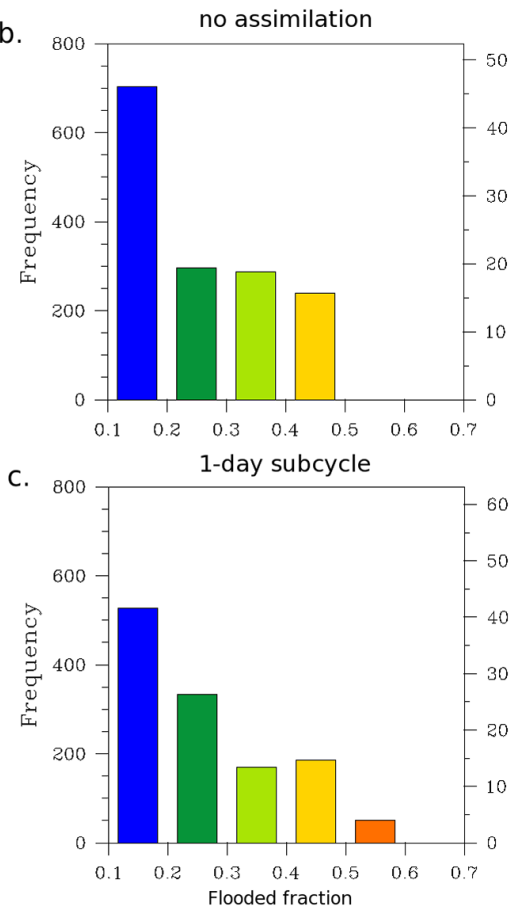

Figure 18. Frequency of flood events over the delta classified by intensity (flooded fraction). Only the pixels with a flooded fraction higher than $10 \%$ are considered for the calculation.

\subsection{Water storage variations}

Ideally, for water resource management applications and for making reliable future water resource projections, global hydrologic models should be able to reasonably simulate water storage variations in regional to large-scale continental reservoirs including rivers, groundwater, aquifers and floodplains. It is then of interest to see if DA can improve the simulation of these water variations. Figure 19 shows the relative water storage variations in four continental reservoirs (river, floodplains, aquifers and soil) for the truth (red), without assimilation (black), 1-day subcycle (blue) and 3-day subcycle assimilations (green). For each reservoir, the 20-day running average water storage variations are divided by the averaged water storage over the period of assimilation. The maximum relative water storage variation ranges from $6 \%$ in the river reservoir to about $30 \%$ in the floodplain reservoir, which is not negligible. In the four reservoirs, the simulations with assimilation better represent the amplitude and the phase of the water storage variations. The assimilation seems to be useful for better representing anomalies in continental reservoirs, which are subject to many uncertainties. However, it should be noted that the physical representativeness of these storage values is not guaranteed due to the lack of monitoring data.

\section{Discussion}

Optimization of the Manning coefficient using a DA methodology leads to a significant improvement of the water levels over the Niger River, and also at the eight locations with gages. The relative error of the Manning coefficient is reduced ( $40 \%$ reduction) and it globally converges towards an optimal value despite potential problems related to equifinality. The relative error of the water level is globally improved (a $30 \%$ reduction) and the amplitude of the water level is closer to the truth with assimilation than without assimilation. Discharge is also improved by the assimilation, but to a lesser extent than for the water levels (7\%). Moreover, the proposed methodology results in a better prediction of flood event occurrence and intensity in the inner delta and better simulates water storage anomaly maxima and minima in several reservoirs, especially the groundwater and the aquifer reservoirs, for which the temporal evolution is difficult to observe. This study is promising since, to our knowledge, no large-scale assimilation applications exist for the optimization of spatially distributed hydrological parameters. It shows SWOT observations would be useful for the improvement of CHSs. This method could lead to a better representation of the water cycle in climate prediction applications, but could also be used for large-scale water resource management applications. Finally, there is no clear advantage difference between the two subcycle orbits used for this study; each has better skill for certain situations. 

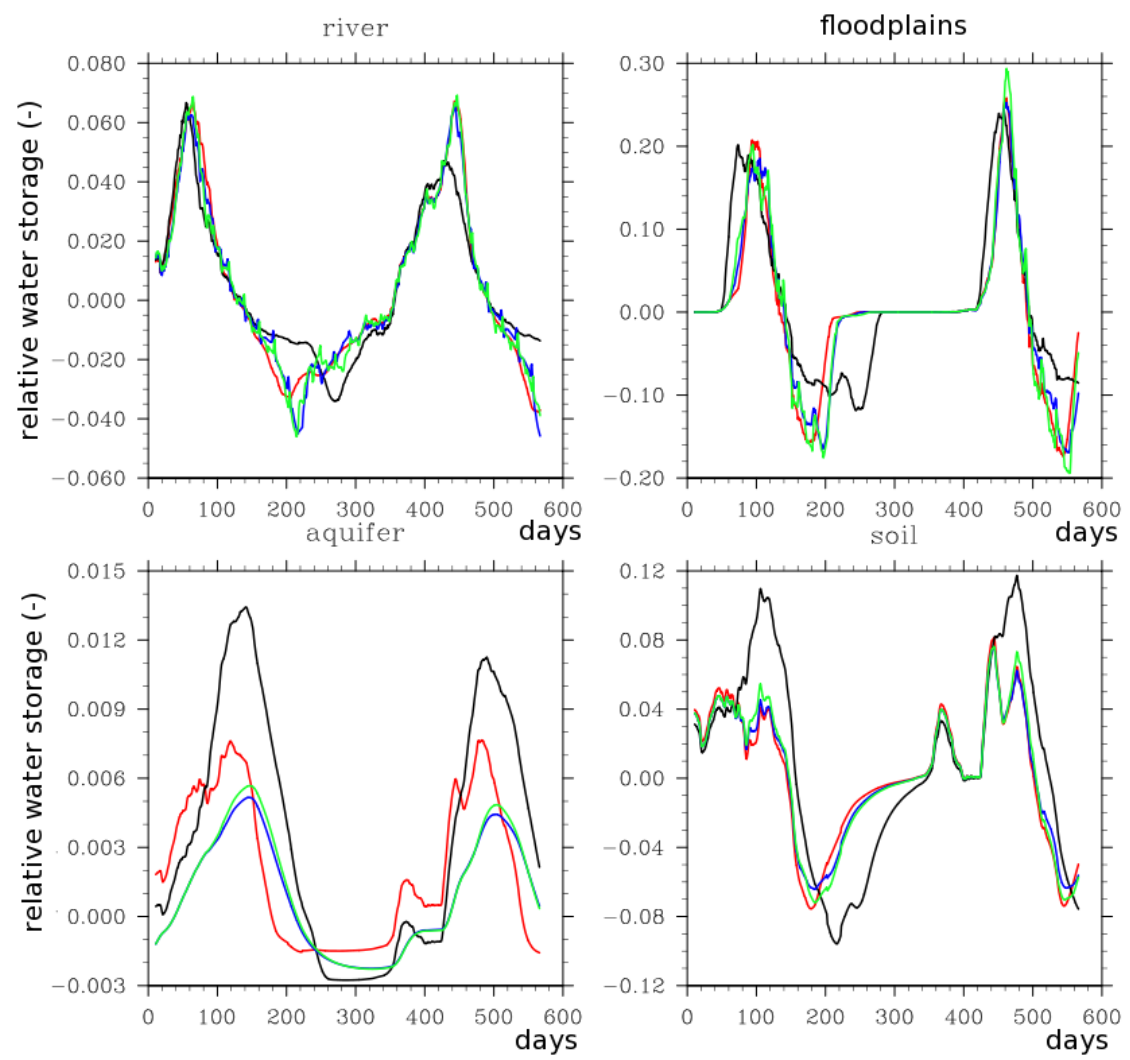

Figure 19. Relative water storage variations in the river, the floodplains, the aquifer and the soil reservoirs for the truth (red), no assimilation (black), 1-day orbit subcycle (green) and 3-day subcycle assimilations (blue). For each reservoir, the 20-day running average water variations are divided by the averaged water storage over the period of assimilation (from June 2002 to December 2003).

This study has some limitations and several assumptions should be noted. The assumption of the white noise error for SWOT observations is probably too optimistic. Furthermore, no correlation of the measurement errors along the swath has been assumed. Estimating satellite observation error sources has been the subject of several studies at the French space agency (CNES) in recent years. Initially, a white noise was introduced within the SWOT water level along track altimetric estimate in order to represent the error due to satellite observations (Biancamaria et al., 2011). Lion (2012) presents methods to simulate, in a more realistic manner, different sources of SWOT satellite observation errors. These errors are generally due to several factors such as satellite attitude, baseline error, phase unwrapping errors, etc. These errors are not always Gaussian and do not always have a mean value of 0 . A perspective for improvement of the assimilation methodology proposed in this study is to introduce these errors into the assimilation system in order to get a more realistic estimation of SWOT observation errors and of the error covariance matrix $\mathbf{R}$. However, their introduction in the system is not obvious and requires the use of a different assimilation filter due to the aforementioned Gaussian issue. Indeed, the Gaussian error distribution along SWOT tracks does not ensure that the error of the observation vector, $\boldsymbol{y}^{0}$, is
Gaussian. Yet, the Gaussian nature of the observation error is a strong assumption of the EKF and possible solutions to get around this limitation exist, such as the use of an ensemble Kalman filter or a particle filter.

The hypothesis that the Manning coefficient uncertainties are the only source of model errors is obviously a rather simple assumption since other errors, such as those related to precipitation forcing uncertainties, riverbank-full depth error or the relatively simple ISBA-TRIP physics, can also be the sources of significant modeling errors. It could be potentially interesting to perform the assimilation on an ensemble of perturbed runs in order to take into account several uncertainty scenarios and the estimation of the background modeling matrix could be done using an ensemble method (Evensen et al., 2004). Within the framework of a real-data experiment, accounting for various sources of errors via Manning control will lead to improved Manning values that should not be interpreted as physical values. Modeling assumptions also put a limitation on the DA performance in the context of realdata experiments. For example, it is assumed in the TRIP model that geomorphological parameters such as the Manning coefficient are constant in time, which is a significant assumption, especially in a region with a strong seasonal climate variability, such as the Niger Basin. Hopefully, SWOT 
observations will help to correct this problem, for example, using this method to build seasonal climatologies of key parameters. To exploit this possibility, a further OSSE study could be done, in which the "true" Manning coefficient varies seasonally.

Additionally, this study was done within the context of OSSE, in which the truth was issued from a reference ISBA-TRIP simulation. This allowed for an evaluation of the methodology but makes the improvements on roughness, level, flow and storage highly correlated. Moreover, the OSSE does not guarantee the physical representativeness of the corrected values of the Manning coefficient since the background and the observations are issued from the same model. For these reasons, the performance of the DA will need to be re-evaluated with real observations. In the study presented here, the truth and the perturbation are based on the same physical parameterizations: this is not true when real data are used. Therefore, the assimilation should be applied using either real observations of water level, or water level issued from a different model, such as a hydrodynamic model. In further studies, longer assimilation windows could be exploited but also require a bigger storage capacity which must be considered for the choice of the assimilation window size.

Finally, this method must be applied to other ISBA-TRIP parameters and for other large-scale basins to evaluate its global application capability. It is not guaranteed that a methodology, which works for a specific basin, could be used for all other major basins (with different climates, geology, etc.). Ongoing work is focused on applying the methodology herein to other basins. These proposed improvements aim at ensuring that the assimilation methodology will be applicable when real SWOT data area be available.

\section{Conclusions}

This study presents a simple method for assimilating SWOT virtual water level into a large-scale coupled land-surface hydrology model (TRIP-ISBA) in order to improve estimates of the required global hydrological model input parameters. In this case, the assimilation is used for the correction of a single parameter which is the Manning coefficient. To accomplish this, an OSSE was performed, using virtual SWOT observations of water levels. Two orbits, with different subcycles but with the same 22-day repeat period, have been considered to generate the observations (1-day and 3-day subcycles), each one providing a specific spatial and temporal coverage of the domain. Uncertainties on the estimation of the Manning coefficient are assumed to be the only sources of modeling errors. The EKF algorithm was applied every 2 days (the length of the assimilation window) to compute an optimal Manning coefficient (analysis). The Manning coefficient globally converged for both orbital subcycles to the same average value, the convergence being faster for the 3- day subcycle orbit. The method leads to a global reduction of $40 \%$ of the Manning coefficient error over the river. This correction significantly improved the water levels (the error has been reduced by $30 \%$ for the river) and, to a lesser extent, discharge ( $7 \%$ of reduction of the error which can be significant for the Niger River in terms of water resources considering that its mean annual discharge is $6000 \mathrm{~m}^{3} \mathrm{~s}^{-1}$ ). Moreover, the biggest improvements were observed downstream of the river (Lokoja), which is a valuable result for climate applications which require estimation of the discharge at large river mouths.

This method gives a promising perspective for globalscale applications, and it could be extended to other large basins. However, several relatively simple hypotheses have been made, and these should be addressed and refined in future studies. The context of the OSSE allows for the evaluation of the model but does not guarantee the physical representativeness of the corrected values obtained in this study. Moreover, other sources of uncertainties should be assumed for the assimilation, such as rainfall errors and/or riverbankfull depth. Modeling errors such as those from the ISBA land surface parameterization should be considered, such as that pertaining to runoff. It was also considered in this work that observation and modeling errors were not correlated in space and time, which might not be realistic. The use of more realistic errors simulated by Lion (2012) in the framework of the SWOT mission prelaunch investigations will be considered in future studies.

Another perspective consists in the application of this method to other TRIP parameters, or several parameters at a time. Correction of ISBA parameters, such as those controlling subgrid runoff for example, is also planned but must be considered carefully as the impact on the river is less direct. Before the satellite launch, the AirSWOT airborne campaign will provide SWOT-like data sets of water level, which will enable studies using a more realistic SWOT DA application, instead of the observing simulation system experiment presented here. Even if this airborne campaign does not cover the Niger Basin, it will potentially provide a better observation error model. Yet, using more complex observations and model errors might require a modification of the assimilation scheme to overcome extremely stringent EKF filter assumptions of Gaussian unbiased errors. Possible assimilation techniques to test are the ensemble Kalman filter or the particle filter.

Acknowledgements. This work is supported by the African Monsoon Multidisciplinary Analysis (AMMA) project and the Surface Water Ocean Topography (SWOT) satellite mission project of the Centre National d'Etudes Spatiales (CNES). The diverse studies presented in this paper would not have been possible without the valuable contribution of the Autorite du Bassin du Niger(ABN).

Edited by: F. Tian 


\section{References}

Alsdorf, D. E., Rodriguez, E., and Lettenmaier, D. P.: Measuring surface water from space, Rev. Geophys., 45, RG2002, doi:10.1029/2006RG000197, 2007.

Andersen, I., Dione, O., Jarosewich-Holder, M., and Olivry, J.-C.: The Niger river basin: A vision for sustainable management, World Bank, Washington, DC, 2005.

Andreadis, K. M., Clark, E. A., Lettenmaier, D. P., and Alsdorf, D. E.: Prospects for river discharge and depth estimation through assimilation of swath-altimetry into a rasterbased hydrodynamics model, Geophys. Res. Lett., 34, L10403, doi:10.1029/2007GL029721, 2007.

Arora, V. K. and Boer, G. J.: A variable velocity flow routing algorithm for GCMs, J. Geophys. Res., 104, 30965-30979, doi:10.1029/1999JD900905, 1999.

Bates, P. and De Roo, A.: A simple raster-based model for flood inundation simulation, J. Hydrol., 236, 54-57, doi:10.1111/j.17521688.2001.tb05522.x, 2000.

Baup, F., Mougin, E., de Rosnay, P., Timouk, F., and Chenerie, I.: Surface soil moisture estimation over the AMMA Sahelian site in Mali using ENVISAT/ASAR data, Remote Sens. Environ., 109, 473-481, doi:10.1016/j.rse.2007.01.015, 2007.

Beven, K. and Kirkby, M.: A physically-based variable contributing area model of basin hydrology, Hydrolog. Sci. B., 24, 43-69, 1979.

Biancamaria, S., Bates, P., Boone, A., and Mognard, N.: Large-scale coupled hydrologic and hydraulic modelling of the $\mathrm{Ob}$ river in Siberia, J. Hydrol., 379, 136-150, doi:10.1016/j.jhydrol.2009.09.054, 2009.

Biancamaria, S., Durand, M., Andreadis, K., Bates, P., Boone, A., Mognard, N., Rodriguez, E., Alsdorf, D., Lettenmaier, D., and Clark, E.: Assimilation of virtual wide swath altimetry to improve Arctic river modeling, Remote Sens. Environ., 115, 373381, doi:10.1016/j.rse.2010.09.008, 2011.

Boone, A., Calvet, J.-C., and Noilhan, J.: Inclusion of a Third Soil Layer in a Land Surface Scheme Using the Force-Restore, Method, J. Appl. Meteorol., 38, 1611-1630, 1999.

Bouttier, F. and Courtier, P.: Data assimilation concepts and methods, ECMWF, 1999.

Chow, V. T., Maidment, D. R., and Mays, L. W.: Applied hydrology, MacGraw-Hill series in water resources and environmental engineering series, 1989.

Cogley, J. G.: The Albedo of Water as a Function of Latitude, Mon. Weather Rev., 107, 775-781, doi:10.1175/15200493(1979)107<0775:TAOWAA>2.0.CO;2, 1979.

Decharme, B. and Douville, H.: Introduction of a sub-grid hydrology in the ISBA land surface model, Clim. Dynam., 26, 65-78, doi:10.1007/s00382-005-0059-7, 2006.

Decharme, B., Douville, H., Boone, A., Habets, F., and Noilhan, J.: Impact of an Exponential Profile of Saturated Hydraulic Conductivity within the ISBA LSM: Simulations over the Rhône Basin, J. Hydrometeorol., 7, 61-80, doi:10.1175/JHM469.1, 2006.

Decharme, B., Douville, H., Prigent, C., Papa, F., and Aires, F.: A new river flooding scheme for global climate applications: Off-line evaluation over South America, J. Geophys. Res., 113, D11110, doi:10.1029/2007JD009376, 2008.
Decharme, B., Alkama, R., Douville, H., Becker, M., and Cazenave, A.: Global Evaluation of the ISBA-TRIP Continental Hydrological System. Part II: Uncertainties in River Routing Simulation Related to Flow Velocity and Groundwater Storage, J. Hydrometeorol., 11, 601-617, doi:10.1175/2010JHM1212.1, 2010.

Decharme, B., Alkama, R., Papa, F., Faroux, S., Douville, H., and Prigent, C.: Global off-line evaluation of the ISBA-TRIP flood model, Clim. Dynam., 38, 1389-1412, doi:10.1007/s00382-0111054-9, 2011.

Drusch, M., Scipal, K., de Rosnay, P., Balsamo, G., Andersson, E., Bougeault, and Viterbo, P.: Towards a Kalman Filter based soil moisture analysis system for the operational ECMWF Integrated Forecast System, Geophys. Res. Lett., 36, L10401,doi:10.1029/2009GL037716, 2009.

Durand, M., Andreadis, K., Alsdorf, D., Lettenmaier, D., Moller, D., and Wilson, M.: Estimation of bathymetric depth and slope from data assimilation of swath altimetry into a hydrodynamic model, Geophys. Res. Lett., 35, L20401, doi:10.1029/2008GL034150, 2008.

Durand, M., Rodriguez, E., Alsdorf, D. E., and Trigg, M.: Estimating River Depth From Remote Sensing Swath Interferometry Measurements of River Height, Slope, and Width, IEEE J. Sel. Top. Appl., 3, 20-31, doi:10.1109/JSTARS.2009.2033453, 2010.

Evensen, G.: Sampling strategies and square root analysis schemes for the EnKF, Ocean Dynam., 54, 539-560, doi:10.1007/s10236004-0099-2, 2004.

Hunter, N., Bates, P., Horritt, M., and Wilson, M.: Simple spatially-distributed models for predicting flood inundation: A review, Geomorphology, 90, 208-225, doi:10.1016/j.geomorph.2006.10.021, 2007.

Knighton1998] Knighton D.: Fluvial forms and processes : A new perspective, Hodder Arnold Publication, Routledge, 400 pp., 1998.

Lion, C.: Simulation des données SWOT haute résolution et applications à l'étude de l'estuaire de l'Amazone, Ph.D. thesis, Univ. Paul Sabatier - Toulouse III, 2012.

Masson, V., Le Moigne, P., Martin, E., Faroux, S., Alias, A., Alkama, R., Belamari, S., Barbu, A., Boone, A., Bouyssel, F., Brousseau, P., Brun, E., Calvet, J.-C., Carrer, D., Decharme, B., Delire, C., Donier, S., Essaouini, K., Gibelin, A.-L., Giordani, H., Habets, F., Jidane, M., Kerdraon, G., Kourzeneva, E., Lafaysse, M., Lafont, S., Lebeaupin Brossier, C., Lemonsu, A., Mahfouf, J.-F., Marguinaud, P., Mokhtari, M., Morin, S., Pigeon, G., Salgado, R., Seity, Y., Taillefer, F., Tanguy, G., Tulet, P., Vincendon, B., Vionnet, V., and Voldoire, A.: The SURFEXv7.2 land and ocean surface platform for coupled or offline simulation of earth surface variables and fluxes, Geosci. Model Dev., 6, 929-960, doi:10.5194/gmd-6-929-2013, 2013.

Michailovsky, C., Milzow, C., and P., B.-G.: Assimilation of radar altimetry to a routing model of the Brahmaputra River, Water Resour. Res., 49, 1-10, doi:10.1002/wrcr.20345, 2013.

Miller, Z. F., Pavelsky, T. M., and Allen, G. H.: Quantifying river form variations in the Mississippi Basin using remotely sensed imagery, Hydrol. Earth Syst. Sci. Discuss., 11, 35993636, doi:10.5194/hessd-11-3599-2014, 2014.

Noilhan, J. and Planton, S.: A Simple Parameterization of Land Surface Processes for Meteorological Models, Mon. Weather Rev., 117, 536-549, 1989. 
Oki, T. and Sud, Y. C.: Design of Total Runoff Integrating Pathways (TRIP) - A Global River Channel Network, Earth Interact., 2, 1-37, doi:10.1175/10873562(1998)002<0001:DOTRIP>2.3.CO;2, 1998.

Papa, F., Prigent, C., Aires, F., Jimenez, C., Rossow, W. B., and Matthews, E.: Interannual variability of surface water extent at the global scale, 1993-2004, J. Geophys. Res., 115, D12111, doi:10.1029/2009JD012674, 2010.

Pavelsky, T. M. and Smith, L. C.: RivWidth: A software tool for the calculation of river widths from remotely sensed imagery, IEEE Geosci. Remote Sens. Lett., 5, 70-73, 2008.

Pedinotti, V., Boone, A., Decharme, B., Crétaux, J. F., Mognard, N., Panthou, G., Papa, F., and Tanimoun, B. A.: Evaluation of the ISBA-TRIP continental hydrologic system over the Niger basin using in situ and satellite derived datasets, Hydrol. Earth Syst. Sci., 16, 1745-1773, doi:10.5194/hess-16-1745-2012, 2012.

Pereira-Cardenal, S. J., Riegels, N. D., Berry, P. A. M., Smith, R. G., Yakovlev, A., Siegfried, T. U., and Bauer-Gottwein, P.: Real-time remote sensing driven river basin modeling using radar altimetry, Hydrol. Earth Syst. Sci., 15, 241-254, doi:10.5194/hess-15-2412011, 2011.
Pistocchi, A. and Pennington, D.: European hydraulic geometries for continental scale environmental modelling, J. Hydrol., 329, 553-567, doi:10.1016/j.jhydrol.2006.03.009, 2006.

Rodriguez, E.: SWOT Science Requirements Document, JPL Document, 11, 2012.

Salamon, P. and Feyen, L.: Assessing parameter, precipitation, and predictive uncertainty in a distributed hydrological model using sequential data assimilation with the particle filter, J. Hydrol., 376, 428-442, doi:10.1016/j.jhydrol.2009.07.051, 2009.

Santos Da Silva, J. and Calmant, S.: Mapping of the extreme stage variations using ENVISAT altimetry in the Amazon Basin Rivers, Int. Water Technol. J., 2, 14-25, 2012.

Yamazaki, D., O’Loughlin, F., Trigg, M. A., Miller, Z. F., Pavelsky, T. M., and Bates, P. D.:Development of the Global Width Database for Large Rivers, Water Resour. Res., 50, 3467-3480, doi:10.1002/2013WR014664, 2014.

Yoon, Y., Durand, M., Merry, C., Clark, E., Andreadis, K., and Alsdorf, D.: Estimating river bathymetry from data assimilation of synthetic SWOT measurements, J. Hydrol., 464, 363-375, doi:10.1016/j.jhydrol.2012.07.028, 2012. 